\title{
The rotating cylinder electrode for studies of corrosion engineering and protection of metals - an illustrated review
}

\author{
F.C. Walsh, ${ }^{1,2,{ }^{*}}$ G. Kear, ${ }^{1,3}$ A.H. Nahlé, ${ }^{4}$ J.A. Wharton ${ }^{2}$, L.F. Arenas ${ }^{1}$ \\ ${ }^{1 .}$ Electrochemical Engineering Laboratory, Engineering Sciences, University of \\ Southampton, UK. \\ 2. National Centre for Advanced Tribology at Southampton, Engineering Sciences, University \\ of Southampton, UK. \\ 3. Present address: Wellington, New Zealand. \\ 4. Department of Chemistry, College of Sciences, University of Sharjah, Sharjah, \\ PO Box 27272 United Arab Emirates. \\ *Author for correspondence; f.c.walsh@soton.ac.uk
}

\begin{abstract}
The uniform flow generated at moderate rotation speeds and ability to control mass transport rates to the cylindrical surface together with uniform current- and potential distributions make the RCE attractive for turbulent flow studies of corrosion and protection. Controlled flow and mass transport are characterised by peripheral velocity, Reynolds number, mass transport coefficient and Sherwood number. Important aspects in corrosion include metal dissolution, oxygen reduction, the stability of surface oxide films and the porosity of protective coatings. Computational studies facilitate simulation of fluid flow, current distribution and mass transport; multiphase electrolytes and nanofluids have been experimentally studied over the last decade. Diverse uses of the RCE include cathodic protection, corrosion inhibitors and protective coatings. Single metal, alloy, nanostructured and coated metal electrodes are illustrated by examples; areas needing further R \& D are indicated.
\end{abstract}

Key words: erosion, hydrodynamics, mass transfer, tribology, turbulence. 


\section{Highlights}

- Engineering science and practical features of the RCE are reviewed.

- Fluid flow around the RCE is normally turbulent; mass transport is predictable.

- Hybrid devices include bi-electrodes and combined micro/macro electrodes.

- RCE studies include inhibitors, flow-corrosion, coatings and surface films.

- Studies have diversified to nanofluids and cells having controlled current density.

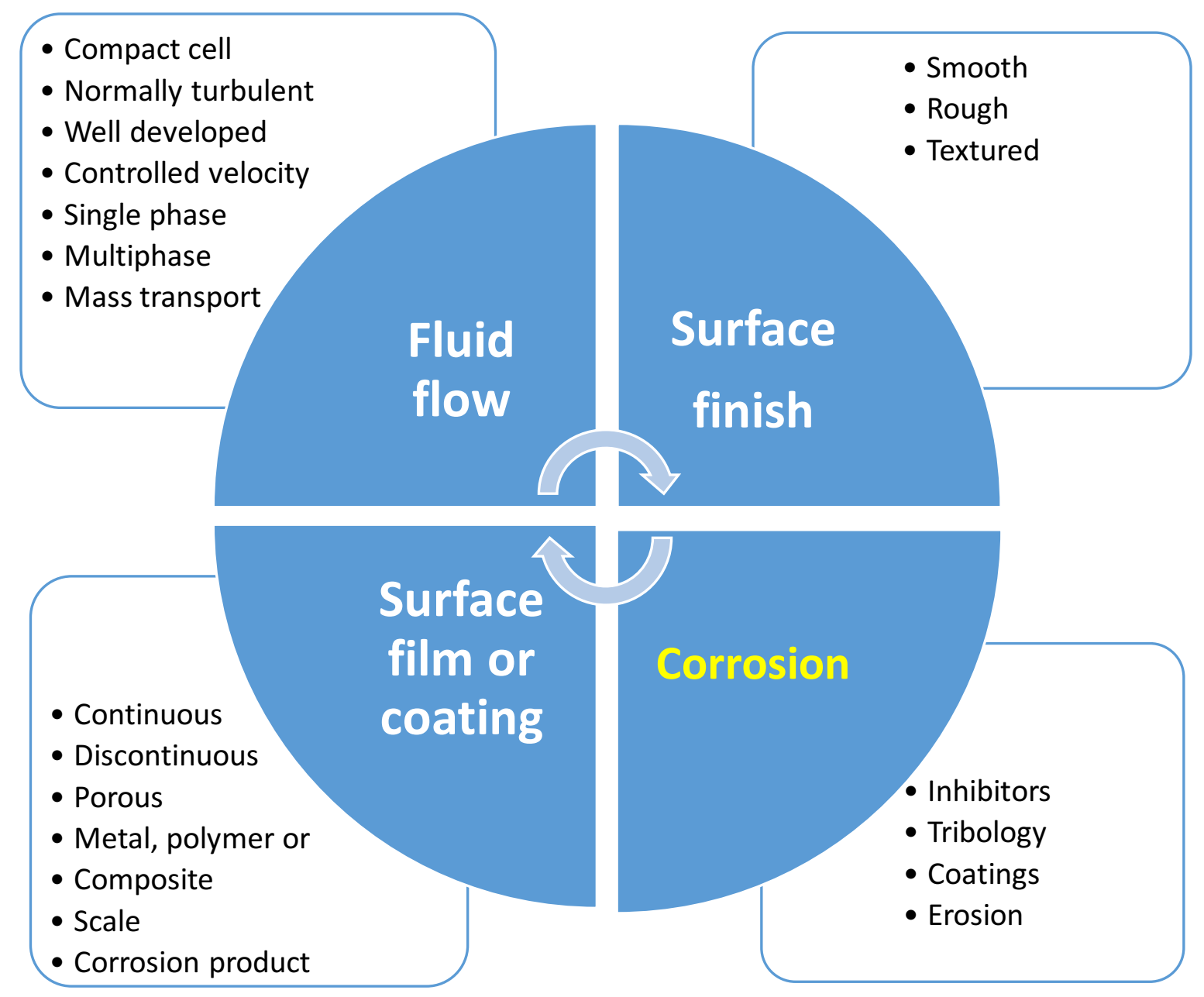




\section{Nomenclature}

\section{Symbol}

$a, b, c, d$

A

$A_{e}$

$c_{b}$

$c_{s}$

C

$d$

$d_{p}$

$D$

E

$E_{\text {cor }}$

$f$

F

$g$

$h$

j

jo

$j_{L}$

$j_{x}$

jave

K

$K_{\text {total }}$

$K_{\text {erosion }}$

$K_{\text {corr }}$

$\Delta K_{\text {synergy }}$

$k_{m}$

$l_{b}$

$l$

$L$

$M$

N

$n$

$x$

$r$

$r_{1}$

$r_{2}$

$R$

$R_{e}$

$R_{p}$
Meaning

Constants in equation (16)

Aperture of short mesh of the expanded metal of RCE

Electrode area per unit electrode volume

Bulk concentration of electroactive species

Concentration at the electrode surface

Capacitance (under charge transfer controlled conditions)

Diameter of rotating cylinder electrode

Diameter of particle

Diffusion coefficient of electroactive species

Electrode potential

Open-circuit corrosion potential

Friction factor

Faraday constant

Distance from RCE to insulator sleeve

Height of rotating cylinder electrode

Current density

Exchange current density

Limiting current density

Local current density at a distance $x$ along the cathode measured from the high current density end

Average current density

Stern-Geary constant in equation (19)

Overall erosion-corrosion rate

Pure erosion rate

Pure corrosion rate

Synergy term for erosion-corrosion rate

Mass transport coefficient

Base length

Length of RCE

Length of Hull cell cathode

Ratio of deposits thickness at predetermined positions

Normalised amount of metal at time $t$ compared to zero

RCE peripheral velocity exponent in equation (19)

Distance along the RCE length

Radius of RCE

Internal radius of the expanded metal $\mathrm{RCE}$

External radius of the expanded metal of RCE

Molar gas constant

Resistance (under charge transfer controlled conditions)

Polarisation resistance

\section{Units}

dimensionless

$\mathrm{cm}$

$\mathrm{cm}^{-1}$

$\mathrm{mol} \mathrm{cm}{ }^{-3}$

$\mathrm{mol} \mathrm{cm}{ }^{-3}$

$\mathrm{F}$

$\mathrm{cm}$

$\mathrm{cm}$

$\mathrm{cm}^{2} \mathrm{~s}^{-1}$

$\mathrm{V}$

$\mathrm{V}$

dimensionless

$\mathrm{C} \mathrm{mol}^{-1}$

$\mathrm{cm}$

$\mathrm{cm}$

$\mathrm{A} \mathrm{cm}^{-2}$

$\mathrm{A} \mathrm{cm}^{-2}$

$\mathrm{A} \mathrm{cm}^{-2}$

$\mathrm{A} \mathrm{cm}^{-2}$

$\mathrm{A} \mathrm{cm}^{-2}$

$\mathrm{V}$

$\mathrm{g} \mathrm{cm}^{-2} \mathrm{~s}^{-1}$

$\mathrm{g} \mathrm{cm}^{-2} \mathrm{~s}^{-1}$

$\mathrm{g} \mathrm{cm}^{-2} \mathrm{~s}^{-1}$

$\mathrm{g} \mathrm{cm}^{-2} \mathrm{~s}^{-1}$

$\mathrm{cm} \mathrm{s}^{-1}$

$\mathrm{cm}$

$\mathrm{cm}$

$\mathrm{cm}$

dimensionless

dimensionless

dimensionless

$\mathrm{cm}$

$\mathrm{cm}$

$\mathrm{cm}$

$\mathrm{cm}$

$\mathrm{J} \mathrm{K}^{-1} \mathrm{~mol}^{-1}$

ohm

ohm 


$\begin{array}{lll}t & \text { Time } & \mathrm{s} \\ t_{\text {total }} & \text { Overall batch time } & \mathrm{s} \\ T & \text { Temperature } & \mathrm{K} \\ U & \text { Peripheral velocity of rotating cylinder electrode } & \mathrm{cm} \mathrm{s}^{-1} \\ z & \text { Electron stoichiometry } & \text { dimensionless }\end{array}$

\section{Dimensionless groups}

$\begin{array}{lll}\mathrm{Fr} & \text { Froude number } & \text { dimensionless } \\ \text { Le } & \text { Dimensionless length } & \text { dimensionless } \\ \text { Re } & \text { Reynolds number } & \text { dimensionless } \\ \text { Sc } & \text { Schmidt number } & \text { dimensionless } \\ \text { Sh } & \text { Sherwood number } & \text { dimensionless }\end{array}$

\section{Greek letters}

$\begin{array}{lll}\alpha_{c} & \text { Cathodic transfer coefficient } & \text { dimensionless } \\ \beta & \text { Porosity } & \text { dimensionless } \\ \delta_{N} & \text { Nernst diffusion layer thickness } & \mathrm{cm} \\ \varepsilon & \text { Surface roughness } & \mathrm{cm} \\ \gamma & \text { Mass transport enhancement factor due to jet flow } & \text { dimensionless } \\ \phi & \text { Current efficiency } & \text { dimensionless } \\ \eta & \text { Overpotential } & \mathrm{V} \\ v & \text { Kinematic viscosity of electrolyte } & \mathrm{cm}^{2} \mathrm{~s}^{-1} \\ \rho & \text { Fluid density } & \mathrm{g} \mathrm{m}^{-3} \\ \tau & \text { Shear stress } & \mathrm{Pa}^{-1} \\ \omega & \text { Rotation speed } & \mathrm{rad} \mathrm{s}^{-1}\end{array}$



Abbreviations
BRCE bimetallic rotating cylinder electrode
CE counter electrode
CRODACE combined rotating disc and cylinder electrode
DRCE double rotating cylinder electrode
DSA dimensionally stable anode
EDX energy dispersive $\mathrm{x}$-ray
EIS electrochemical impedance spectroscopy
EN electrochemical noise
HAZ heat affected zone (near a weld)
HVOF high velocity oxy fuel
ICCP impressed current cathodic protection
LERCE line electrode in an RCE
LPR linear polarisation resistance
LSV linear sweep voltammetry
MOCVD metal organic chemical vapour deposition
NAB nickel aluminium bronze
PLD pulsed laser deposition
PTFE polytetrafluoroethylene
RANS Reynolds averaged Navier-Stokes
RCE rotating cylinder electrode
$\mathrm{RCH} \quad$ rotating cylinder Hull
RDE rotating disc electrode
RE reference electrode
SCE saturated calomel (reference) electrode
SEM scanning electron microscopy
SRCE stepped rotating cylinder electrode
WE working electrode
XRD X-ray diffraction 


\section{Contents}

1. Introduction

2. Electrode and cell geometry

2.1 Types of electrode

2.2 Aspects of cell design and construction

3. Fluid flow and mass transport

3.1 General expressions

3.2 Friction factor

3.3 Dimensionless group mass transport correlations

4. Potential- and current distributions

5. Fundamental corrosion studies

5.1 Open-circuit electrode potential vs. time

5.2 Mass transport controlled current density $v s$. rotation speed

5.3 Corrosion rate measurements

5.4 Corrosion inhibitors

6. Corrosion engineering

6.1 Cathodic protection and galvanic corrosion

6.2 Liquid flow and current density

7. Tribology

7.1 Multiphase fluids

7.2 Nanofluids

8. RCE studies of protective coatings

9. Modified RCEs

10. Conclusions

11. Aspects deserving further $R \& D$

(Approx. 17,800 words, 153 refs, 5 tables, 15 figures and 20 equations/reactions.) 


\section{Introduction}

The rotating cylinder electrode (RCE), which has developed as a compact, hydrodynamic electrode since the 1950s, is not as well-known as the rotating disc electrode (RDE) which normally provides controlled mass transfer in laminar flow for electrode kinetic studies. The uniform turbulent flow generated at moderate rotation speeds around an inner RCE and the ability to control mass transport rates to the cylindrical surface together with uniform currentand potential distributions make the RCE attractive for controlled flow corrosion and protection studies. In comparison to static planar electrodes in channel flow, the RCE has the advantage of being compact and easy to assemble or modify; it does not require large electrolyte volumes or pumped flow loops. Simple RCE studies are commonly performed with similar rotators to RDEs and many modified RCE geometries are possible (section 2). Controlled turbulent flow and mass transport (section 3 ) are characterised by the peripheral velocity, $U$ and the Reynolds number, $R e$ with the mass transport coefficient, $k_{m}$ and Sherwood number, Sh being important to describe mass transport rates. Important flow affected reactions under turbulent conditions in corrosion include metal dissolution, oxygen reduction, the stability of surface oxide films and the porosity of protective coatings.

The uniform reaction environment around an RCE concerns not only flow but potential and current distributions (section 4). Fundamental and engineering studies of corrosion using the RCE under open-circuit, controlled potential or constant current are considered in sections 5 and 6. The major applications of the RCE include tribology (section 7) and protective organic, metal or composite coatings (section 8). While most RCE studies have concerned simple, single electrode RCEs, a diverse array of multi- and hybrid electrode designs for specialised use are considered in section 9 . 
Other important electrodes in flow corrosion include the wall-jet disc electrode and (rectangular or circular cross-section) channel flow [1,2]. The book by Papavinasam [3] provides a useful compilation of information on corrosion measurements using controlled flow geometries, including the RCE. The wall-jet disc electrode tends to be less convenient and more difficult to precisely control and analyse while channel flow test sections suffer from hydrodynamic edge effects and require relatively high electrolyte volumes and sufficient space for a pumped flow loop.

Figure 1 shows a definition sketch of a RCE in a constant volume of electrolyte, indicating important dimensions and operational parameters. The time-line of Figure 2 highlights important contributions during the development of RCE fundamentals and studies on the corrosion of metals, while Figure 3 illustrates various interactive aspects of RCE design and use. Early studies included fluid flow and mass transport to hydrodynamically smooth RCE surfaces $[4,18]$ and the importance of surface roughness [5]. Such studies, particularly in the case of electroplating of metals, were reviewed by Gabe in 1974 [6] and this early review briefly considered early corrosion studies. In 1978, Selman and Tobias [7] compiled the mass transport correlations of diverse electrode geometries, including contributions on rotating and non-rotating cylinders, some of which have not been revisited. A later review by Gabe and Walsh on RCEs has highlighted reactor designs for metal ion removal from dilute process solutions [8]. Silverman considered the RCE for velocity sensitive corrosion in 1984 [9] and 1988 [19]. In 1993 Poulson contributed a useful paper on hydrodynamic effects on corrosion [20] while Silverman contributed a review on corrosion studies at the RCE in 2004, which focused on peripheral velocity and mass transfer [11]. The continued development of the RCE in applied electrochemistry was highlighted in 1998 [10], while the electrodeposition of metals was extensively reviewed in 2005 [16]. 
The major features of the RCE for studies of corrosion and protection of metals are highlighted in Table 1. The RCE is an elegant, controlled flow electrode, offering good mass transport control, a well-documented mass transport dependence on rotation speed and considerable versatility regarding the choice of material, surface texture and roughness as well as the possibility of multiple electrodes for galvanic or mechanistic studies.

Smooth RCEs have seen extensive use to quantify mass transport controlled corrosion of copper, NAB and stainless steel in chloride solutions by Kear et al. in 2004 [12-14,21]. The last few years have seen increasing interest in electrolytes containing suspended nanoparticles and the RCE has been used as a controlled, turbulent flow geometry to investigate erosioncorrosion synergy in such nanofluids [17]. A general summary of corrosion and protection studies at RCEs is attempted in section 10 followed by a highlighting of critical areas needing further R \& D in the final section.

\section{Electrode and cell geometry}

\subsection{Types of electrode}

Diverse rotating electrodes have been considered for laboratory electrochemical studies. We can group these under four categories, single electrodes, roughened electrodes, bi-electrodes and others, as shown in Figure 4. General features may be highlighted:

a) The single electrode category $[6,8,9]$ includes the rotating cylinder electrode (RCE) and the stepped rotating cylinder electrode (SRCE). Roughened electrodes $[5,6,8,9,11,20]$ include the longitudinal finned electrode, knurled (staggered) diamond pyramid surface electrodes, an RCE wrapped with cylindrical wire electrode and a metal powder deposit on an RCE. 
b) The 'two-electrode' category [10] includes the double rotating cylinder electrode (DRCE).

c) The combined rotating disc electrode and rotating cylinder electrode (CRODACE) may be used on a common shaft.

d) The final electrode category includes micro/macro RCE combinations such as the microline electrode rotating cylinder electrode ( $\mu$-LERCE).

Many of these RCE variants have been used in electroanalysis and studies of electrode kinetics rather than in technological areas such as corrosion or coatings.

As Figure 4 indicates, the RCE surface may be modified by, e.g.:

e) recessing, stepping [22], sleeving [23] or crevice formation,

f) precoating the RCE or formation of a porous film; the RCE surface may be impinged by

g) an electrolyte jet $[24,25]$ or

h) a solid particle [26] or gas stream.

These RCE types, variants and their combinations together with time dependent surface and electrolyte affects provide a rich diversity of controlled flow surface for corrosion studies. Coated or filmed RCEs are considered elsewhere for metal deposition [16].

While many RCE corrosion studies have been targeted to the oil and gas industry, particularly the evaluation of inhibitors, increasing use of RCE electrode and cell designs are being implemented into other sectors, including monitoring of metal release to monitor water quality in closed loop systems [27], selective recovery of $\mathrm{Ag}$ from $\mathrm{Cu}$-containing mining streams [28], conversion of sulfur dioxide [29], industrial nickel ion recovery [30], water decontamination from cadmium [31] and synthesis of hydrogen peroxide [32]. 
The RCE has also proved suitable for non-conventional extreme conditions. For instance, Nor et al. has used an cell/autoclave to achieve up to 350 bar and $300{ }^{\circ} \mathrm{C}$ [33]. Furthermore, Rappleye and Simpson [34] have recently applied RCEs to the measurement of limiting currents in molten $\mathrm{LiCl}-\mathrm{KCl}$ eutectic mixtures containing $\mathrm{UCl}_{3}$ and $\mathrm{MgCl}_{2}$ at $500{ }^{\circ} \mathrm{C}$ in a specially designed electrochemical cell/crucible. The RCE mass-transfer correlations in such media were consistent with those reported in aqueous solutions.

\subsection{Aspects of cell design and construction}

A typical, divided, glass, laboratory cell for RCE studies is shown in Figure 5a) [35]. This versatile cell, which has facilities for temperature control, has a working electrode (RCE) compartment divided from the counter electrode (CE) compartment by an ion exchange membrane. Typically, the WE might have a diameter of $c a .15 \mathrm{~mm}$ and an active length of 20 $\mathrm{cm}$. For convenience and weight reduction, the RCE can be a section of circular pipe or a hollowed out cylindrical bar. Electrically insulating, polymeric end pieces (typically polypropylene or PTFE) serve to define the WE area and minimise unwanted potential-, current- or flow edge effects. The WE compartment has a typical electrolyte volume of 100$2000 \mathrm{~cm}^{3}$, with smaller volumes of $80-250 \mathrm{~cm}^{3}$ often being favoured for rapid benchtop experiments. Extremely small volumes $<10 \mathrm{~cm}^{3}$ are possible using rotating cylindrical wires. The use of a known volume facilitates mean corrosion rate measurements via chemical analysis of the electrolyte. This RCE cell design offers practical advantages over flow-through pipe and annular flow systems [36]. The avoidance of vortex formation and achievement of a mechanical stable, high speed RCE corrosion test cell are considered in several patents, such as a 2001 example from the Saudi Arabian Oil Company [37]. 
The use of an external reservoir with electrolyte flowing through the cell in the batch recirculation mode is commonly used to extend the electrolyte volume up to $100 \mathrm{dm}^{3}$. In a controlled flow loop system, it is also common to provide facilities to monitor $\mathrm{pH}$, temperature, electrolytic conductivity and dissolved oxygen concentration. While the majority of RCE corrosion studies are carried out under atmospheric pressure at a temperature of $20-80{ }^{\circ} \mathrm{C}$, specialist cells have been designed to operate at pressures $<400$ bar and temperatures $<350{ }^{\circ} \mathrm{C}$. The group of Nesic et al. have provided useful descriptions of such flow rigs and cells. For example, a study by Nor et al. concerned the effect of $\mathrm{CO}_{2}$ on corrosion of mild steel in aqueous chloride in a flow loop with an electrolyte volume of $7.5 \mathrm{dm}^{3}$. The 316 stainless steel cell was designed as an autoclave capable of operating at $<350$ bar and $<300{ }^{\circ} \mathrm{C}$ [33].

As shown in Figure 5b), lightweight, thin-walled pipe-sections can prove convenient to fabricate hollow cylindrical materials, such RCE designs have been utilised by Walsh et al. [38] for electrodeposition of composite layers containing solid particles in a metal matrix. The corrosion protection offered by such films often exceeds that of single-phase metal electrodeposits, the included particles providing better coverage and modified nucleation/growth of metal on the substrate.

Flow around the stepped RCE, SRCE which involve local disturbance of electrolyte flow has been considered by Yang et al. [22] while Kear et al. [23] have measured mass transport to such electrodes achieved by an outer sleeve to define the step profile. Typically, $0.48 \mathrm{~mm}$ to $2.05 \mathrm{~mm}$ high steps were achieved by electrodeposition of copper; the local limiting current density increase was up to 3 times that at a hydrodynamically smooth RCE surface.

Several RCE and cell design features are worth highlighting: 
1. By far the most common and convenient configuration for an RCE is an overhung, vertically rotating cylinder with dry electrical connections between the drive motor and the top of the RCE (Figure 1). Such a design avoids the need for a bottom bearing, and a lower electrolyte seal and is readily achieved by RDE drive control and measurement systems.

2. Common aspect ratio (length /diameter) of RCE of 0.5 to 5 are found in laboratory studies $[16,39,40]$. Long RCEs can present problems with mechanical support and bearing design, limited electrical conductivity and poor mixing of electrolyte flow and stratification of heavier particles in two-phase flow.

3. Larger, scaled-up RCEs require attention to cylinder fabrication to ensure adequate robustness and electrical conductivity, materials such as stainless steel and titanium having moderate conductivity compared to mild steel and much lower conductivity than copper alloys $[41,42]$.

4. RCEs suffering from limited electrical conductivity, perhaps due to thin walled or long cylinders, can suffer from ohmic drops within the electrode phase and non-uniform electrode potential distributions. Such effects can be minimised by the use of separate electrical power and potential sensing brush contacts [43], effective systems being several silver-filled graphite brushes running on a silver-plated copper slip ring, e.g. [44].

5. Inert electrolyte flow baffles are sometimes included in RCE cells, perhaps in the hope of improving mixing. However, the turbulent, 3-dimensional mixing around an RCE rotating at typical speeds $(\operatorname{Re}>200)$ or $\omega>10 \mathrm{rev} \min ^{-1}$ for a $2 \mathrm{~cm}$ diameter cylinder in a solution of kinematic viscosity, $v=1 \mathrm{cS}\left(=1 \times 10^{-2} \mathrm{~cm}^{2} \mathrm{~s}^{-1}\right)$ generates effective turbulence and solution mixing [38] which helps prevent sedimentation of suspended particles in 2-phase electrolytes during erosion-corrosion studies. Indeed, radial baffles can disturb flow uniformity around the RCE while axial baffles have been deliberately used to achieve separation of internal flows, generating a cascade of identical continuous stirred tank reactors, CSTRs in hydraulic series 
for high fractional conversion of reactant concentration decrease in metal ion removal reactors $[40,45]$.

6. In view of the severe mixing engendered by 3-dimensional turbulent core flow around an RCE, secondary flow patterns close to the RCE surface are unusual, in contrast to the spiral morphology patterns occasionally seen in corrosion products on an RCE surface in laminar flow with superimposed helical patterns [35]. The RDE also suffers from pronounced edge effects, especially as the radius increases.

7. While flow distribution is relatively uniform around the cylindrical section of an RCE, it is wise to minimise flow and current edge effects by using inert, electrically insulating end pieces flush mounted on the RCE shaft $[8,10]$.

8. Most workers have chosen to use a single concentric, inert outer electrode as a counter electrode to the RCE, promoting uniform flow and potential distributions. However, examples of up to 6 planar CEs have been used in a hexagonal arrangement $[39,45,46]$, for convenience in material availability. The electrode potential is then time-averaged at the RCE surface, albeit with a superimposed alternating current ripple, which can affect surface morphology or film growth. In specialised cases, the continuity of the CE may be interrupted by the need to incorporate scraper/wiper devices jet impingement or inlet and outlet manifolds [16,39].

9. A deliberate current distribution can be engineered onto an RCE surface by suitable counter electrode geometry and placement, as illustrated by offset anode and high aspect ratio working electrode of the RCH cell [47] in section 4.

10. It is important to consider division of the WE and CE compartments in RCE cells. Cell division may be necessary to prevent the $\mathrm{CE}$ products (e.g. $\mathrm{O}_{2}, \mathrm{Cl}_{2}$ or metal ions from an anode) from interfering with the RCE kinetics. Separation can be achieved by a robust microporous polymer or an ion exchange membrane but adequate sealing and support must be provided. 
Nesic and Carroll [48] have described a horizontal RCE to study the effect of water wetting on $\mathrm{CO}_{2}$ corrosion of mild steel in chloride solution in a 2-phase oil-water electrolyte. Waterhexane was used as a model fluid, with $5-50 \%$ vol. water in a $1 \% \mathrm{w} / \mathrm{v} \mathrm{NaCl}$ electrolyte at $\mathrm{pH}$

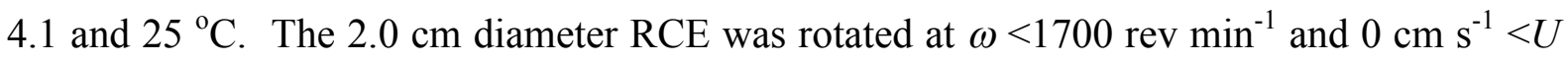
$<180 \mathrm{~cm} \mathrm{~s}^{-1}$. The authors identified threshold peripheral velocity values where the surface became oil wetted and corrosion ceased.

For routine testing of corrosion inhibitors in turbulent flow with the convenience of flat plate samples, rotating cages have been used [49]. Computational flow dynamics simulations have been carried out [50], showing that, for a given cage diameter, the rotational speed is an important parameter. Many authors have failed to realise that the major parameter governing flow conditions and the mass transfer controlled corrosion rate is the Reynolds number, $R e$, i.e., the peripheral cylinder velocity, $U$ for a known diameter cylindrical cage in a constant viscosity electrolyte.

\section{Fluid flow and mass transport}

\subsection{General expressions}

The transition from laminar to turbulent flow is characterised by a dimensionless group, the Reynolds number, which expresses the ratio of inertial and viscous forces in a solution. For an RCE with a characteristic diameter, $d$ and radius, $r$, the Reynolds number may be defined as:

$$
R e=\frac{U d}{v}=\frac{\omega r d}{v}
$$

$U$, the peripheral RCE velocity, is related to the rotation speed, $\omega$ by: 


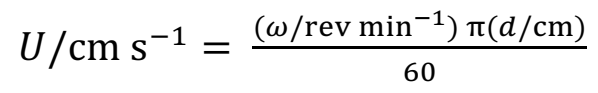

and $v$ is the kinematic viscosity of the electrolyte.

Under typical laboratory conditions, the RCE experiences turbulent flow over a wide range of rotation speeds. Taking the case of a $1.5 \mathrm{~cm}$ diameter RCE having a smooth surface finish, turbulence establishes at $\omega>200 \mathrm{rev} \mathrm{min}^{-1}$. This is in marked contrast to a smooth $\mathrm{RDE}<1 \mathrm{~cm}$ in diameter, which might maintain laminar flow up to $2000 \mathrm{rev} \mathrm{min}^{-1}$ in the absence of electrolyte vortexing and gas bubbles. Useful laboratory notes on RCE rotation speed and mass transport for common laboratory electrodes are available from suppliers, e.g. [51,52] and it is important to note that the RCE geometry in corrosion testing has become part of recognised ASTM standards [53,54].

\subsection{Friction factor}

For the RCE, the Reynolds number can be related to the dimensionless friction factor, $f$ via [5]:

$$
\log R e=0.1737\left(\frac{f}{2}\right)^{-0.5}-\log \left(\frac{f}{2}\right)^{0.5}+0.2979
$$

Within the turbulent region $\left(10^{3}<\operatorname{Re}<10^{5}\right)$ an approximation is [4]:

$$
\frac{f}{2} \approx 0.0794 R e^{-0.30}
$$

In the case of laminar flow at Reynolds numbers below 200 [8]: 


$$
\frac{f}{2}=2 R e^{-0.3}
$$

The shear stress at the wall, $\tau$ is a measure of the rate of momentum transfer to the surface at which fluid flow is acting. For the general case of fluid flow at a solid surface [9]:

$$
\tau=\frac{f}{2} \rho U^{2}
$$

where, $U$ is the fluid velocity. For the RCE, the shear stress at the wall, $\tau_{R C E}$ is given by [9]:

$$
\tau_{R C E}=\frac{f}{2} \rho \omega^{2} r^{2}
$$

Combination of equations (6) and (7) for a hydrodynamically smooth RCE in fully developed turbulent flow leads to:

$\tau_{R C E}=0.079 R e^{-0.30} \rho \omega^{2} r^{2}$

It has been proposed that the modelling of corrosion mechanisms as a function of flow rate can be achieved between different geometries via equality of shear stress [19]. For single-phase, undisturbed flow, the use of this criterion implies that the fluid affected mechanism in one configuration is duplicated in the other but the approach does not always result in an equality in the rates of mass transfer and corrosion $[19,20]$.

\subsection{Dimensionless group mass transport correlations}


Mass transfer studies of the RCE have mostly been empirical due to the nature of turbulent flow. The most established dimensionless group correlation for the hydrodynamically smooth RCE in turbulent flow is due Eisenberg, Tobias and Wilke in 1954 [4]:

$S h=0.079 R e^{0.70} S c^{0.356}$

This correlation was achieved as the mean of three solid dissolution systems and two electrochemical reactions in five solutions of various concentrations using cylinders of varying diameter and annulus gap width. The entire study covered a range of Schmidt number from 835 to 11,490 and Reynolds number from 112 to 241,000 . Combination of all the mass transfer data produced an average deviation from a general correlating curve of limiting current density $v s$. Reynolds number of $\pm 8.3 \%$. While the maximum deviation of individual points was as high as $32 \%$, the correlation is remarkable in covering a diverse range of scale and process conditions. The diameter of the cylinder rather than the annulus gap width between the rotating cylinder and an external stationary wall was taken as the characteristic length in both the Reynolds and Sherwood numbers.

In terms of limiting current density, cylinder diameter and peripheral velocity, this relationship leads to an analogous relationship to the Levich equation $[4,18]$ :

$j_{L R C E}=0.079 z F c_{b} d^{-0.3} v^{-0.344} D^{0.644} U^{0.7}$

Robinson used an alternative dimensionless group correlation [55] to obtain the following expression for limiting current density: 
$j_{L}=0.169 z F c_{b} d^{-0.34} v^{-0.32} D^{0.67} U^{0.66}$

Using the cylinder radius as the characteristic length, equation (11) becomes [25]:

$S h=0.064 R e^{0.70} S c^{0.356}$

$S h$ is the Sherwood number describing the mass transport due to forced convection, Re is the Reynolds number describing fluid flow and $S c$ is the Schmidt number describing the transport properties of the electrolyte.

The last equation leads to an expression for limiting current density in terms of cylinder radius and rotation speed, [25]:

$j_{L R C E}=0.064 z F c_{b} D^{0.64} v^{-0.34} r^{0.40} \omega^{0.70}$

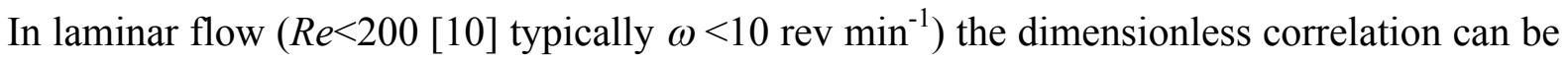
written $[8,11]$ :

$S h=0.97 R e^{0.64} S c^{0.33}$

Table 2 provides a review of published dimensionless group correlation data for turbulent flow at a fully smooth RCE, highlighting the large variation in correlation constants compared to an RDE. This is particularly true for the constant ' $a$ '. Typically, a linear correlation having standard deviation of around $17 \%$ and up to $18 \%$ deviation from the ETW correlation is 
involved [56]. Incorporating the friction factor described in equation (4), into the ETW correlation produces a modified Chiton-Colburn type relationship [5]:

$$
S h=\left(\frac{f}{2}\right) R e S c^{0.356}
$$

Similar relationships have been derived for rough surfaces $[5,8,63,64]$. The effect of roughness for the RCE in the presence of static turbulence promoters has been considered [38,57,65-68] with an emphasis on metal ion recovery [69,70]. For fully roughened surfaces, Poulson experimentally determined dimensionless group correlations showing a similar form for diverse geometries [64].

Controlled studies at high mass transport conditions are enabled by rotating cylinder electrodes $[5,6,8,11,18]$, due to their uniform primary and secondary current distributions and easily achievement of turbulent flow [71,72]. Provided that the turbulence is only due to electrode rotation, dimensionless group correlations can be used to describe the mass transport rate $[5,9,18]:$

$$
S h=a R e^{b} S c^{c} L e^{d}
$$

$a, b, c$, and $d$ are empirical constants and $L e$ is the dimensionless length, which in this case is given by the surface roughness divided by the electrode diameter. Equation (16) can be also expressed as:

$$
\frac{k_{m} d}{D}=a\left(\frac{U d}{v}\right)^{b}\left(\frac{v}{D}\right)^{c}\left(\frac{\varepsilon}{d}\right)^{d}
$$


where $D$ is the diffusion coefficient and $U$ is the peripheral velocity. These correlations use the diameter of the inner rotating cylinder electrode as the characteristic length. Preferably, the form of the mass transport correlation arises from a mathematical analysis of experimental data, showing the importance of electrode geometry, cell geometry and fluid flow. The electrode roughness, as well as electrolyte composition physical properties determine the values of $L e$ and the empirical constants [22,23,41,43,61,73,74]. Expressions for less common Non-Newtonian fluid flow and horizontal rotating cylinders have been considered by Singh [75] and Meštrović-Markovinović [76], respectively.

Mass transport enhancement at a RCE under turbulent regime can be compared to the correlation for smooth electrode surfaces $[4,18]$. The effect of several roughened surfaces is shown in Figure 6. Table 3 presents the corresponding empirical correlations for various roughened electrodes. Surface roughness at RCEs can be also achieved by electrodeposition of metals. The resulting mass transport and electrode surface area has been implemented in metal recovery from diluted solutions $[60,62,77,78]$. The process was carried out at a current range between 50 A to 5000 A with high efficiency and according to the empirical dimensionless group correlation:

$$
\frac{k_{m} d}{D}=0.079\left(\frac{U d}{v}\right)^{0.92}\left(\frac{v}{D}\right)^{0.36}
$$

Other mass transport enhancement strategies for RCEs include electrolyte jet flow [25] and application of ultrasound [79].

\section{Potential- and current distributions}


Normally, an RCE is designed to provide uniform current density and electrode potential distributions along the length of the circumferential surface and polymeric insulators are strategically placed at the top and bottom to minimise edge effects. In special cases, however, a controlled gradation of current density is sought, examples including cathodic protection and critical pitting studies. An earlier review of RCE developments [9] included rotating cone electrodes surrounded by a static cylindrical counter electrode to achieve a controlled gradation of current density along the height (length) of a vertical cathode under controlled, turbulent flow conditions. Such a geometry, having a 52 degree apex angle cone, has been extensively studied by Afshar et al. [80].

A much easier geometry to engineer and scale is a central RCE with an offset counter electrode, a simple static disc being used for the latter by two groups of workers, largely with electrodeposition of metals in mind. Landolt et al. introduced such a rotating cylinder Hull cell in 1992 [81-83], which has been extensively studied by Walsh et al. $[47,84]$. The cell has a deliberately non-uniform potential- and current distribution during copper deposition from acid sulphate solutions [47] along a vertical cathode experiencing controlled turbulent flow via a controlled rotation speed of the rotating cylinder Hull cell. The current distributions have been computed by a finite element model and confirmed by experiments on copper deposition from an acid sulphate solution. Figure 7 shows the geometry of the RotaHull ${ }^{\circledR}$ cell [47], in which the rotating cylinder electrode (height $8.0 \mathrm{~cm}$, diameter $0.6 \mathrm{~cm}$ ) is surrounded by a concentric polycarbonate insulator $(15.0 \mathrm{~cm}$ length, $4.4 \mathrm{~cm}$ internal diameter, $5.0 \mathrm{~cm}$ external diameter $)$ with an access to the cylindrical mesh counter electrode $(5.2 \mathrm{~cm}$ internal diameter, $2.5 \mathrm{~cm}$ height) at the bottom. Auxiliary components include: PTFE cylindrical insulators, a stationary polycarbonate bottom support and a cylindrical glass electrolyte container. 
The cell design produces a controlled, deliberately non-uniform, current and potential distribution along the working RCE length as a result of its varying distance to the counter electrode. The highest current density and electrode potential are found at $x=0 \mathrm{~cm}$ because it is nearest to the counter electrode. The lowest current density and potential occurs at $x=8 \mathrm{~cm}$, which is furthest from the counter electrode. The bottom polycarbonate static support has a negligible shielding effect on the current and potential distributions along the working electrode, which are uniformly distributed in the radial direction along the $\mathrm{RCH}$. As shown in Figure $7 \mathrm{c}$ ), the primary current distribution is the least uniform along the electrode length, followed by the secondary current distribution. The tertiary current distribution shows the least deviation from a theoretical uniform distribution.

Different types of reactions can be studied in the RCH cell, including high speed electroplating and deposition of alloy coatings, such as Cu-Sn (bronze) [84], and mass transport effects under turbulent flow conditions. The non-uniform distribution allows many data points to be collected in a single experiment. While the cell was originally developed for electroplating of single metals, it is well suited to the characterisation of other coating processes including metal alloys, conducting polymers and metal-included particle composites. The opportunity exists to redevelop the RCH cell for corrosion and protection studies.

\section{Fundamental corrosion studies}

In a simple classification, electrochemical corrosion studies can be considered to belong to the following groups: a) potentiometry (electrode potential, usually vs. time), b) voltammetry (current vs. potential, often under linear potential sweep conditions), or c) chronoamperometry (current vs. time, often following a potential or velocity step). Examples of such data for corrosion of metals at the RCE are provided in this section. 


\subsection{Open-circuit electrode potential vs. time}

The monitoring of open-circuit electrode potential under free corrosion conditions is a simple but important technique in corrosion studies. The value and time dependence of the opencircuit potential can provide general information on the existence and stability of surface films.

Kear et al. studied the open-circuit potential of freshly polished $\mathrm{Cu}$, cupronickel, nickel aluminium bronze and Ferralium SD40 superduplex stainless steel with time in filtered seawater [14]. After initial immersion in each of the electrolytes, it was observed that for a given angular velocity, the corrosion potential, $E_{c o r}$, tended to became more negative with time until a stable potential was achieved. Figure 8 provides an example of this behaviour. For the copper based materials, the value of the stabilised potential became more negative as the rotation rate of the electrode was increased. An 'inflection' ennoblement observed was seen as a result of time-dependent changes in the surface film on the Ferralium but did not occur with copper or NAB.

At a RCE, the open circuit potential stabilisation of the $\mathrm{Cu}$-based metals was significantly shorter than at an RDE [35]. In the filtered seawater stabilisation times of 1000,700 and $300 \mathrm{~s}$ were required for copper, $90-10 \mathrm{Cu}-\mathrm{Ni}$, and $\mathrm{NAB}$, respectively. These values represent $17 \%$, $56 \%$ and $63 \%$ those measured for the RDE. RCE pre-polarisation and equilibration times are given in Table 4.

Galvanic electrometric reduction was incorporated in the study of the surface species present at the copper based RCEs immediately after polishing and after the OCP equilibration period at $200 \mathrm{rev} \mathrm{min}^{-1}$. Figure 9 describes the reduction curves produced at the RCEs in $\mathrm{pH} 8$ 
orthophosphate buffer solution. The black plots describe the reduction of the freshly polished films and the red lines describe the reduction of the species present after the OCP stabilisation period at $200 \mathrm{rev} \mathrm{min}^{-1}$. The estimated potentials associated with each wave at the metal are shown in Table 4. The composition and thickness of the films at the RCEs were different for each metal and each underwent considerable transformation during the OCP stabilisation period. This was attributed to dissolution as the dichlorocuprous anion and, in the case of the 90-10 copper nickel, some conversion of the cuprous oxide film. The estimated film thickness

is given in Table 5. Two potential arrests were produced at the copper RCE. These are attributable to the reduction of (1) $\mathrm{Cu}_{2} \mathrm{O}$ and (2) $\mathrm{CuO}$ from a surface film having two layers. After equilibration, the thickness of both layers was reduced to the point where no species could be detected on the surface. For polished 90-10 copper nickel, a large single wave was produced, probably due to the reduction of $\mathrm{Cu}_{2} \mathrm{O}$. This was dissolved during the equilibration period and replaced with another more noble wave which would be due to the formation of another species, possibly $\mathrm{Cu}(\mathrm{OH})_{2}$ or $\mathrm{CuO}$. Freshly polished NAB showed two ill-defined waves (designated as $\mathrm{Cu}(\mathrm{OH})_{2}$ and $\mathrm{Cu}_{2} \mathrm{O}$ ) which were completely absent after equilibration.

\subsection{Mass transport controlled current density vs. rotation speed}

In a series of papers by Kear et al. [12-15], oxygen reduction at NAB in aqueous chloride electrolytes was considered. The cathodic polarisation behaviour was examined in fully characterised seawaters (filtered and artificial) using the RDE and the RCE [12]. Linear sweep voltammetry and a potential step, current transient technique were used to examine the charge transfer and mass transfer controlled cathodic response as a function of both laminar and turbulent fluid flow. For freshly polished surfaces, the rate of irreversible charge transfer controlled oxygen reduction is controlled by a 2-electron process and hydrogen evolution is only significant at potentials more negative than $-1.0 \mathrm{~V} v s$. SCE. In another paper [13], the 
authors examined the electrochemical characteristics of anodic dissolution of NAB (at both the RDE and the RCE) were used in the derivation of the corrosion potential, $E_{c o r}$. The dependency of the overall corrosion rate on fluid flow conditions was determined using the high reproducible laminar and turbulent fluid flow regimes at the RDE and RCE geometries. The influence of Reynolds number, $R e$ on the mass transfer coefficient, $k_{m}$ as a function of laminar flow (RDE) and fully turbulent flow (RCE) for hydrodynamically smooth surfaces was carefully examined. The authors used a potential step, current transient technique at low values of positive polarisation to accurately determine the flow dependency of NAB dissolution under conditions of controlled laminar and turbulent fluid flow. At potentials close to $E_{c o r}$, the shortterm anodic polarisation behaviour of freshly polished NAB in dilute chloride media is analogous to unalloyed copper where the reaction rate was under mixed control. At the corrosion potential, the charge transfer controlled reduction of oxygen and the mixed charge and mass transfer controlled anodic dissolution determine the corrosion behaviour of the freshly polished material. Corrosion rates derived from Tafel extrapolation were proportional to angular velocity and ranged from approximately 4 to $12 \mu \mathrm{A} \mathrm{cm}$ in filtered and artificial seawaters at $25{ }^{\circ} \mathrm{C}$. LSV was used to examine the passivation of NAB as a function of fluid velocity. At relatively high RDE rotation speeds ( $\left.>1800 \mathrm{rev} \mathrm{min}^{-1} ;>188 \mathrm{rad} \mathrm{s}^{-1}\right)$, the material exhibited a self-passivating mechanism which significantly improved corrosion resistance. The $\mathrm{Al}_{2} \mathrm{O}_{3}$-based passivation mechanism of the material was dependent on both applied potential and ambient mass transfer conditions.

\subsection{Corrosion rate measurements}

Kear et al. used the RCE to calculate the corrosion rate of copper, $\mathrm{Cu}-\mathrm{Ni}$, NAB and Ferralium SD40 superduplex stainless steel in seawater at $298 \mathrm{~K}$. The order of susceptibility to corrosion was $90-10 \mathrm{Cu}-\mathrm{Ni} \cong \mathrm{NAB}>\mathrm{Cu}>$ freshly polished Ferralium SD40. Unlike the superduplex 
stainless steel, all the copper-based metals exhibited a strong rotation rate dependence on corrosion current density, the rate of corrosion increased with electrode peripheral velocity. At $4800 \mathrm{rev} \mathrm{min}^{-1}$, the rates of corrosion measured at the 90-10 copper nickel and the NAB were 9 and $10 \mu \mathrm{A} \mathrm{cm}^{-2}$, respectively [35]. Linear polarisation resistance, $R_{p}$ measurements were used to relate the corrosion rate to RCE peripheral velocity, $U$ from the relationship between the inverse polarisation resistance and $U$ :

$$
1 / R_{p}=K U^{n}
$$

Mean values of the empirical Stern-Geary constant, $K$ and velocity exponent, $n$ were found from numerous experiments and plots of $1 / R_{p} v s$. the logarithm of $U$. A summary of the corrosion rates of these materials as a function of RCE peripheral velocity is shown in Figure 10. The equivalent corrosion current density measured at the copper was $6 \mu \mathrm{A} \mathrm{cm}^{-2}$. Freshly polished Ferralium SD40 showed a corrosion current density of $c a .1 \mu \mathrm{A} \mathrm{cm}{ }^{-2}$.

Electrochemical techniques other than linear polarisation e.g. [85] can be used to study corrosion rates at RCEs. For instance, Lu et al. used electrochemical impedance spectroscopy (EIS) to determine the corrosion rate of iron in spent liquors from the alumina refining industry at temperatures up to $230^{\circ} \mathrm{C}$ [86], validating their results against linear polarisation resistance. Silverman [87] also applied EIS to the estimation of corrosion rates, highlighting the need of careful circuit model choice. Reasonably accurate values could be obtained from EIS, as shown by gravimetric corrosion analysis. Another method involves electrochemical noise (EN) measurement, which has been used by Galvan-Martinez et al. [88] to study the effect of turbulent flow on the corrosion of API X60 in seawater by employing two rotating cylinder electrodes. Statistical methods were used to analyze the EN, indicating that the rate of the 
observed localized corrosion increased as a function of rotation rate, particularly under turbulent flow.

\subsection{Corrosion inhibitors}

The RCE is a very convenient electrode for controlled flow studies and an ideal probe for studying corrosion processes in turbulent flow, since the rate of corrosion is often governed by the rate of mass transport. The corrosion process may be monitored by weight loss measurements, or electrochemically such as linear polarisation resistance (LPR) or electrochemical impedance spectroscopy (EIS). Several previous studies [89-93], have employed an RCE to assess the efficiency of corrosion inhibitors for oil and gas pipelines, and Yaakob and Ismail [94] investigated the effect of the $\mathrm{FeCO}_{3}$ corrosion products on a imidazoline inhibitor. Ige et al. [95] evaluated the performance of a commercial corrosion inhibitor based on a mixture of anhydrides, polyamines, ethoxylated imidazolines, quaternary ammonium salts, ethanodiol and thioalcohol in flow-induced corrosion and erosion-corrosion environments under the influence of shear stress and sand particles impingement. Neville [26] used an RCE to show that erosion-corrosion occurred due to the removal of the inhibitor film from the steel surface by the high flow velocity and sand particles in oil and gas producing wells. The efficiency of imidazoline-based inhibitor on the $\mathrm{CO}_{2}$ corrosion of carbon steel (with $1 \%$ wt. chromium) in a deoxygenated $5 \%$ wt. $\mathrm{NaCl}$ solution saturated with $\mathrm{CO}_{2}$, was carried out by LPR and EIS using an RCE [96]. Galvan-Martinez et al. used twin RCE electrodes and electrochemical noise techniques to study the corrosion of API X60 steel [88] in sea water, and later the corrosion inhibition of API X52 steel [97]. Carew et al. [98] studied the corrosion inhibition of quaternary ammonium salts on carbon steel in sea water injection system. 3amino-1, 2, 4, triazole was used as corrosion inhibitor for API X52 pipeline steel in $\mathrm{CO}_{2}$ saturated brine solution using RCE [99]. Others [100], have evaluated thioglycolic acid (TGA), 
diethylenetriamine (DETA), and naphthene acid imidazolines as corrosion inhibitors of precorroded $\mathrm{N} 80$ steel in $\mathrm{CO}_{2}$-saturated $1 \%$ wt. $\mathrm{NaCl}$ solution using an RCE. Linear polarization resistance measurement and electrochemical impedance spectroscopy were used with a rotating cylinder electrode as a technique to study the corrosion inhibition of a natural piper beetle and green tea extracts on API X52 steel in $\mathrm{NaCl}$ solution [101]. Galvan-Martinez et al. studied the effect of $0.25,0.5$ and $0.75 \mathrm{ppm}$ concentrations of biocide on the corrosion of pipeline steel in seawater [102], under laminar and turbulent flow regimes at standard conditions, with an RCE at rotation rates up to $1000 \mathrm{rev} \mathrm{min}^{-1}$. LPR and steady state polarization showed that turbulent flow significantly increased the rates of the observed localised corrosion.

The corrosion inhibition of other useful alloys has also been studied by RCE. For instance, the inhibition of heat exchanger fouling in alumina refining processes by green products [103], or the inhibition of process equipment steel by aspartic acid [104]. Liu et al. [105] have used the RCE to simulate the hydrodynamic condition of the automobile cooling system to electrochemically investigate the inhibition effect of $\mathrm{Ce}$ (III) ion on the corrosion of 3003 aluminium alloy (AA3003) in glycol-water. The inhibition efficiency of benzotriazole at 90$10 \mathrm{Cu}-\mathrm{Ni}$ alloys in acid, deaerated environments has been considered by Maciel et al. [106]. In their studies on a $1.2 \mathrm{~cm}$ diameter $\left(A=2.94 \mathrm{~cm}^{2}\right)$ mild steel RCE at peripheral velocities of 25 , 50 and $100 \mathrm{~cm} \mathrm{~s}^{-1}$ in aerated $\mathrm{HCl}$ and $\mathrm{H}_{2} \mathrm{SO}_{4}$, Musa et al. [107] have reported that a higher peripheral velocity resulted in a positive shift in the corrosion potential, increasing the cathodic current density and lowering the anodic current density. Figure 11 shows Nyquist plots from EIS studies, showing the effect of rotation speed, which allowed the authors to fit their results to an equivalent circuit and determine effective $C$ and $R_{e}$ values for charge transfer resistance in the presence of controlled inhibitor adsorption on the mild steel surface. RCE was also used 
for studying the corrosion kinetics in natural waters [108] and the general stability of the corrosion inhibitor films [107,109-112].

Relatively few corrosion studies have considered the importance of roughness development during attack on the metal surface. A recent study has attempted to quantify this effect for a mild steel RCE in $4 \mathrm{~mol} \mathrm{dm}^{-3} \mathrm{HCl}$ after 3 hours immersion at $80{ }^{\circ} \mathrm{C}$ [113]. Bead blasting and $\mathrm{SiC}$ abrasive paper grinding were used to pre-roughen surfaces. The authors considered equations (8) and (14), utilising the average surface roughness, $R_{a}$ and the skewness factor to characterise surface texture. The corrosion rate was found to be proportional to $R_{a}$ to the power 0.31 in laminar flow and 0.59 in turbulent flow, the effect of roughness being more pronounced under turbulent conditions.

\section{Corrosion engineering}

\subsection{Cathodic protection and galvanic corrosion}

Potentiostatic impressed current cathodic protection (ICCP) of the bimetallic RCE was demonstrated using a bimetallic couple between 90-10 copper-nickel/NAB and copper/NAB RCEs on a common shaft [114]. All data were measured directly using the bimetallic RCE or calculated indirectly from available single metal polarisation measurements. The data in each case originated from experimental application of the steady-state potential step current transient technique.

Dual RCEs for bimetallic (galvanic) corrosion are considered further in section 9.

\subsection{Liquid flow and current density}

Two common strategies are used to ensure uniform flow and current density around an RCE WE. Firstly, placing the counter electrode at a sufficiently large distance from the WE, e.g., in 
a compartment separated from the RCE WE by a microporous glass or polymer or ion exchange membrane (as in Figure 5a). This has the advantage of excluding products, such as oxygen evolution, chlorine evolution or metal ion contamination, from influencing the kinetics at the RCE. Secondly, a full, concentric counter electrode can be deployed although this can prove costly in the case of precious metals.

In practice, geometries include one or more flat plate counter electrodes, often arranged in a symmetrical manner around a central RCE. Two planar counter electrodes were used by Walsh et al. in numerous metal deposition studies [39]. The groups of Nava and Gonzalez have considered flow around, and mass transport to, 4-plate, 6-plate and concentric counter electrodes [45,46]. Rivero et al. studied a 6-plate mixed metal oxide coated DSA around a 3.8 cm diameter, smooth RCE cathode rotating at 400-1100 rev $\min ^{-1}$ used to deposit copper from $0.019 \mathrm{~mol} \mathrm{dm}^{-3} \mathrm{Cu}^{2+}$ in $1 \mathrm{~mol} \mathrm{dm}^{-3} \mathrm{H}_{2} \mathrm{SO}_{4}$ [45]. Their concentration decay data was considered to fit predictions from the Reynolds averaged Navier-Stokes (RANS) equation. Rivera and Nava found that the 4-plate counter electrode gave rise to a similar average mass transport to the RCE as a concentric geometry [46]. Employing the RANS equation, the same group developed and validated a model of the turbulent flow inside a continuous electrochemical reactor using an RCE [115].

Atempa et al. [116] simulated turbulent flow around an RCE by the standard $k-\varepsilon$ and $k-\omega$ models and related it to the enhanced corrosion rate of API 5L-X56 steel in brine environment in the presence of kerosene and $\mathrm{H}_{2} \mathrm{~S}$. The corrosion products were studied via $\mathrm{XRD}$, showing that the formation oxides and sulphides developed passivating coatings. Galván-Martínez et al. [117] studied the effect of mass transport on the corrosion of AISI X52 mild steel in deaerated $3.5 \% \mathrm{NaCl}$ at $60{ }^{\circ} \mathrm{C}$, containing $\mathrm{H}_{2} \mathrm{~S}$ at 0.7 bar, using an $\mathrm{RCE}$ at a peripheral velocity up to 400 
$\mathrm{cm} \mathrm{s}^{-1}$. The mass transport controlled rate of corrosion depended on peripheral velocity raised to the power of 0.7 , as expected for a smooth RCE in turbulent flow.

\section{Tribology}

\subsection{Multiphase fluids}

The use of the RCE in tribology has improved our ability to quantify synergy in erosioncorrosion interactions in turbulent flow and to produce velocity-sensitive metal wastage maps for traditional and newer engineering alloys [118]. In addition to classical clay slurries, electrolytes have diversified to include multiphase nanofluid dispersions (section 7.2).

Early studies largely concerned single phase aqueous electrolytes, typically brine or dilute acid while copper and its alloys, ferrous materials and stainless steel are the most commonly studied metals. In the case of single phase fluids, several groups have contributed to an improved understanding of erosion by liquid or impinging solids during electrochemical corrosion, the synergy between these degradation processes being complex and dependent on flow regime, local flow, surface texture, material, texture and electrolyte composition, as well as electrode geometry and flow velocity. As described below, examples of quantitative studies of tribological corrosion have ranged from simple studies of model fluids through to simulations of, and experimental measurements on, industrial fluids.

The tribology literature shows increasing levels of complexity in the electrolyte composition and number of phases present, ranging from single phase solutions to those containing gases such as $\mathrm{H}_{2} \mathrm{~S}$ and $\mathrm{CO}_{2}$ (to simulate sweet and sour corrosion, respectively) or electrolytes containing entrained solids such as alumina or silica (to simulate solid particle impingement and erosion. The presence of dissolved gases such as $\mathrm{CO}_{2}$ or $\mathrm{H}_{2} \mathrm{~S}$ in seawater results in 
aggravated (sweet and sour) corrosion. If solid particles are present, removal of protective films, erosion and wear on the metallic surface can occur by particle impingement, erosion and related effects. The corrosion of the metallic structure under turbulent flow is complex, but this problem has been studied mainly in the oil industry where, multiphase flow, unsteady flow and gases are very important in the mechanism of corrosion. A common need in the petroleum industry is the effect of flow and dissolved gases, such as hydrogen sulphide and carbon dioxide on the type and speed of materials degradation with time.

One approach consists on the study of the tribological properties of electrodeposited coatings at RCEs. For instance, Bengoa et al. [119] have investigated the hardness, roughness and wear resistance of electrodeposited bronze. The coatings were produced at $60{ }^{\circ} \mathrm{C}$ under rotation speeds of 500 or $800 \mathrm{rpm}$, from $\mathrm{Cu}^{2+} / \mathrm{Sn}^{2+}$ plating baths containing phenol sulfonic acid. Despite the superior hardness of the bronze alloy in comparison to $\mathrm{Cu}$, the rough morphology of the coating reduced its wear resistance. A similar study on Co-W coatings was carried out by Silkin et al. [120], although in this case a Hull cell was used in order to assess the effect of current density on the deposit microhardness. The electrodeposition was carried out at $270 \mathrm{rpm}$ from citrate- and gluconate-based electrolytes over the range $0.5 \mathrm{~A} \mathrm{dm}^{-2}$ to $6 \mathrm{~A} \mathrm{dm}^{-2}$.

Most contributions on tribology have, however, focused on the combined and synergistic corrosion-wear effects. Nesic et al. [121] compared the use of an RCE and pipe flow to evaluate the performance of an amidazoline inhibitor on $\mathrm{X} 65$ mild steel in $\mathrm{CO}_{2}$ saturated $3.5 \% \mathrm{NaCl}$ at $20{ }^{\circ} \mathrm{C}$ using fluid velocities in the wide range $0-13 \mathrm{~m} \mathrm{~s}^{-1}$. The RCE had a diameter of $10 \mathrm{~cm}$ and length of $10 \mathrm{~cm}\left(A=314 \mathrm{~cm}^{2}\right)$ rotating at $<5000 \mathrm{rev} \min ^{-1}\left(U<26.2 \mathrm{~m} \mathrm{~s}^{-1}\right)$. The authors found reasonable agreement between the two geometries, allowing for mass transport 
predictions by empirical literature correlations and provided a useful summary of experimental problems encountered using a flow loop [122].

The effect of mass transport on the corrosion of AISI API 5L X65 mild steel in $\mathrm{CO}_{2}$ saturated $3.5 \% \mathrm{NaCl}$ at $50{ }^{\circ} \mathrm{C}$ using a $1.2 \mathrm{~cm}$ diameter, $3.13 \mathrm{~cm}^{2}$ area $\mathrm{RCE}$ at a peripheral velocity up to $314 \mathrm{~cm} \mathrm{~s}^{-1}$ has been studied by Ige et al. [95]. The controlled shear stress was used to quantify the performance of an inhibitor $(<100 \mathrm{ppm})$ in the presence of spheroidal $250 \mu \mathrm{m}$ silica particles $\left(500 \mathrm{mg} \mathrm{dm}^{-3}\right)$. A direct comparison with impingement at ring samples in the same fluid showed different inhibitor efficiencies, which the authors attributed to different shear stress and corrosion surface morphology.

Yuan and Stack used a $3.8 \mathrm{~cm}$ diameter, $1.0 \mathrm{~cm}$ long $\left(A=11.3 \mathrm{~cm}^{2}\right)$ baffled RCE at a peripheral velocity up to $800 \mathrm{~cm} \mathrm{~s}^{-1}$ to study erosion corrosion of a $12 \% \mathrm{Cr}$ steel in deaerated $1 \mathrm{~mol} \mathrm{dm}^{-3}$ $\mathrm{NaOH}$ at an unstated temperature [123]. The alkaline slurry electrolyte contained $275 \mathrm{~g} \mathrm{dm}^{-3}$ alumina particles of 50,100 or $150 \mu \mathrm{m}$ diameter. The authors reported mass loss due to corrosion, erosion or their synergy, the synergistic component being highest for the larger particles at potentials corresponding to active metal dissolution. The authors used a simple equation to express the overall erosion-corrosion rate, $K_{\text {total }}$, as an addition of the rates of pure erosion, $K_{\text {erosion }}$ pure corrosion, $K_{\text {corr }}$ and a synergy term, $\Delta K_{\text {synergy }}$.

$$
K_{\text {total }}=K_{\text {erosion }}+K_{\text {corr }}+\Delta K_{\text {synergy }}
$$

The authors used potential control to cathodically protect the RCE at $-0.9 \mathrm{~V}$ to $-1.0 \mathrm{~V} v s$. $\mathrm{Hg} / \mathrm{HgO}$ in order to establish pure erosion data. At more positive potentials of $0.4 \mathrm{~V}$ to $0.6 \mathrm{~V}$ 
vs. $\mathrm{Hg} / \mathrm{HgO}$, an appreciable synergy term was found, $100 \mu \mathrm{m}$ and $150 \mu \mathrm{m}$ sized particles showing approx. one third the overall weight loss with $50 \mu \mathrm{m}$ particles (Figure 12).

Chen et al. used EIS measurements in a flow loop and at an RCE to evaluate the corrosion rate of a $\mathrm{C}-1018$ mild steel in $\mathrm{CO}_{2}$ saturated brine at $40{ }^{\circ} \mathrm{C}$ [124]. The authors studied the performance of an imidazoline inhibitor under multiphase flow in a $10.2 \mathrm{~cm}$ diameter, $15 \mathrm{~m}$ long acrylic flow loop using ASTM substitute saltwater and $\mathrm{CO}_{2}$. The flow loop system could generate slug flow, pipe flow and multiphase slug flow characterised by a Froude number. A 3 $\mathrm{cm}^{2}$ area RCE in $250 \mathrm{~cm}^{3}$ electrolyte was also utilised with graphite counter electrodes but RCE rotation speeds were not stated. The high shear stress and turbulence due to the mixing vortex and the bubble impact in multiphase flow could enhance corrosion or reduce the inhibition performance of inhibitors, depending on the flow conditions. Labraga et al. [125] have provided a method to study the wall shear stress from a RCE.

\subsection{Nanofluids}

Nanofluids can be defined as fluids having at least one phase of nanometre size. Examples include model systems such as alumina in seawater or silica in natural waters, while nanofluids have become important in offering improved heat transfer in specialised cooling systems. The RCE provides a useful means of studying nanofluids under controlled shear conditions in fully turbulent flow, providing fundamental data to enable use of these fluids as coolants and in composite electrodeposition baths.

Rashidi et al. studied the enhanced corrosion of mild steel in $3.5 \% \mathrm{NaCl}$ at $\mathrm{pH} 8.3$ over 12 hours at $25{ }^{\circ} \mathrm{C}$ containing alumina nanoparticles [17]. A hydrodynamically smooth-rotating cylinder electrode of $6 \mathrm{~cm}$ diameter and $56.5 \mathrm{~cm}^{2}$ area rotating at $415 \mathrm{rev} \mathrm{\operatorname {min } ^ { - 1 }}\left(U=130 \mathrm{~cm} \mathrm{~s}^{-}\right.$ 
${ }^{1}$ ) was used. Although the individual corrosion rate of the steel in the nanoparticle-free fluid was up to $82 \%$ while its erosion rate was approximately $11 \%$ lower, the combined corrosion and erosion in the fluid containing $1 \mathrm{~g} \mathrm{dm}^{-3}$ of spheroidal $20 \mathrm{~nm}$ alumina was superior by $237 \%$. Figure 13 shows the marked increase in corrosion rate experienced in the nanofluid.

A study by Asmara et al. was carried out to determine the erosion corrosion of AISI316 stainless steel in an ethylene glycol coolant containing dispersed titania nanoparticles [126]. The experiments used an RCE of $1.6 \mathrm{~cm}$ diameter and $5.0 \mathrm{~cm}^{2}$ area at a rotational speed of 0 $1800 \mathrm{rev} \min ^{-1}\left(U=151 \mathrm{~cm} \mathrm{~s}^{-1}\right)$ in ethylene glycol at $30-70{ }^{\circ} \mathrm{C}$. Corrosion rate was measured by LPR and erosion was estimated by measuring the average surface roughness. Both corrosion rate and surface roughness were found to increase at higher temperature and higher rotation speed. The erosion-corrosion attack of the nanofluid coolant (of fluid density $=4.23 \mathrm{~g} \mathrm{~cm}^{-3}$ ) was lower under static conditions. Under controlled flow conditions, the maximum synergism between erosion and corrosion occurred at higher temperature and high rotation speed for both solutions.

It is interesting to note that electrodeposition of composite coatings containing included nanparticulate ceramic or polymeric particles in metal matrices such as nickel involves enhanced mass transfer of metal ions to the cathode $[38,126,127]$, representing an opportunity to deploy the RCE for quantitative experimental and modelling studies.

\section{RCE studies of protective coatings}

Coatings are commonly used to protect the metallic components from corrosion and prolong their life. Many corrosion protection techniques have been applied in pipeline, marine, automobiles, aerospace, construction industries, and others. Wear resistance, high-temperature 
stability, and corrosion protection are desirable features of coatings. The RCE offers a controlled turbulent flow environment for controlled shear studies of protective coatings on a small, benchtop scale, which avoids large, complex, pumped flow loops. The diversity of coatings ranges from thin polymer, metal or ceramic films through to complex multiphase coatings such as particles included in electrodeposited metals and alloys. In many cases, electrode rotation poses minimal problems to coating integrity. Paolinelli and Carr [128] have, however, considered the possibility of coating damage due to increased internal stress in coatings due to inertial forces, using $\mathrm{FeCO}_{3}$ films in $\mathrm{CO}_{2}$ corrosion of mild steel as an example.

Jegadeeswaran et al. [129] have used a high velocity oxy fuel (HVOF) process for thermal spraying of an oxide coating to help prevent degradation of turbine alloys. The HVOF sprayed coating comprised $\mathrm{Cr}_{3} \mathrm{C}_{2}-\mathrm{NiCr}$ and $\mathrm{NiCrAlY}$ and imparted enhanced corrosion resistance to titanium-based alloys. Karthikeyan et al. [130] have applied $\mathrm{Zn}-\mathrm{Cr}_{2} \mathrm{O}_{3}$ composite coating on mild steel by electroplating from a cyanide free bath and reported superior mechanical properties and corrosion resistance due to the presence of $\mathrm{Cr}_{2} \mathrm{O}_{3}$ together with the zinc. Lee [131] has protected aluminium alloys from degradation and corrosion with a trivalent chromium coating instead of classical chromate conversion coatings which effectively passivate the metal surface but contain toxic Cr(VI) species. Conrad et al. [132] have developed an electrochemical method for fabrication of corrosion resistant coatings which incorporate layered silicate platelets into zinc-nickel (to combat salt corrosion) and copper-nickel (to combating microbial corrosion); such coatings are important in the oil and gas industry. The coatings showed increasing strength, adhesion, wear and fracture toughness, together with a long service lifetime. 
Conductive polymers are also used for corrosion protection of metals as they can be either chemically or electrochemically deposited on the metal surface causing stabilization of the potential of the metals via formation of protective layer, including some of natural origin [133]. Thompson et al. [134] have developed electroactive polymer coatings for mild steel surfaces and claimed that these films maintained corrosion resistance even when scratched. Kouloumbi et al. [135] studied steel which had been spin-coated with a $70 \mu \mathrm{m}$ thick layer of polymeric particulate composite consisting of an epoxy resin and metal powders (Fe, $\mathrm{Al}, \mathrm{Zn}$ ) as fillers; the addition of the metal powders did not affected the corrosion inhibition provided by the coatings. Hexagonal boron nitride/polymer hybrid thin film coating [136] have been applied on stainless steel for marine corrosion protection and showed improvement in corrosion resistance due to the hydrophobic and dielectric properties of boron nitride. Hybrid organicinorganic $\mathrm{SiO}_{2}-\mathrm{TiO}_{2}$ sol-gels were prepared by Kirtay [137] as corrosion protective coatings on a mild steel substrate by the dip coating technique in combination with heat treatment between $200{ }^{\circ} \mathrm{C}$ and $300{ }^{\circ} \mathrm{C}$. The precursors for coating solutions were glycidoxytrimethoxysilane and titanium tetraisopropoxide. The author showed that the coating film improved the corrosion resistance and reported that the presence of the organic groups reduced the stress and crack formation and improved the elasticity of the coating.

Other protective coatings are based on passive oxide films For instance, Singh et al. [138] reported that coating stainless steel surfaces with alumina using pulsed lased deposition (PLD) showed an excellent corrosion resistance to molten uranium even up to a temperature of 1165 ${ }^{\circ} \mathrm{C}$. The same authors deposited thin film of yttrium oxide $\left(\mathrm{Y}_{2} \mathrm{O}_{3}\right)$ coating on stainless steel substrates using pulsed laser deposition [139], which showed high corrosion resistance to molten uranium. Reactive magnetron sputtering was used for the deposition of cerium oxide thin films for corrosion protection of A11050 and A12024 alloys as an alternative to chromate 
based coating [140]. Fuerbeth et al. [141] have developed glass-like corrosion protective film coatings on aluminium alloy and steel substrates, which were thermally processed at comparatively low temperatures, $c a .500{ }^{\circ} \mathrm{C}$; polymeric sols of $\mathrm{SiO}_{2}-\mathrm{B}_{2} \mathrm{O}_{3}-\mathrm{P}_{2} \mathrm{O}_{5}-\mathrm{Na}_{2} \mathrm{O}$ oxides were used as precursors for the hard, crack-free layers. $\mathrm{Co}_{3} \mathrm{O}_{4}$ protective coatings for $\mathrm{Fe}-22 \mathrm{Cr}$ intermediate temperature solid oxide fuel cells have been prepared by pulsed injection metal organic chemical vapour deposition from a cobalt acetylacetonate precursor [142]. Aluminosilicate corrosion protective coatings were applied on silicon carbide fibres and composites in high temperature structural materials using metal-organic chemical vapour deposition (MOCVD) method [143]. The resulting transparent coatings were amorphous and smooth. Sahu et al. [144] have synthesized graphene oxide (GRO) which was electrochemically deposited on a copper substrate from a solution containing $0.02 \mathrm{~g}$ of GRO and $10 \mathrm{~cm}^{3}$ of 1:50 HDI (poly(hexamethylene) diisocyanate) solution in $0.1 \mathrm{~mol} \mathrm{dm}^{-3} \mathrm{KCl}$. This was followed by chemical reduction of the GRO to graphene by $0.1 \mathrm{~mol} \mathrm{dm}^{-3} \mathrm{NaBH}_{4}$ solution for 5 minutes; then electrochemical polarization studies were carried out on copper, copper/oxidised graphene and copper/reduced graphene in $3.5 \% \mathrm{NaCl}$ solution as shown in Figure 14. The authors claimed that a graphene coating increased the corrosion resistance by a factor of 18 times compared to bare copper.

Electroless nickel coatings are being increasingly used in a variety of applications due to their advantageous chemical, mechanical, and physical properties. Zeller [145] studied the corrosion inhibition mechanism of electroless nickel coatings with high phosphorus content (10 to 11\% wt.) in $5 \% \mathrm{NaCl}$ solutions. A corrosion rate $<1 \mathrm{~mm} \mathrm{y}^{-1}$ was observed at the open-circuit corrosion potential, which reached a steady-state after $c a .24 \mathrm{~h}$, suggesting that accelerated corrosion testing could be achieved. RCE studies demonstrated that the protective film was 
sensitive to wall shear stresses. The authors suggested that the cathodic reaction kinetics are inhibited due to the development of a phosphorus-enriched film.

Composite materials often encompass high performance properties with cost-effectiveness. Protective coatings consisting of inert inorganic particles in a metal matrix, can provide enhanced abrasion and corrosion resistance, which has been exploited for commercial applications. Benea et al. studied and compared the corrosion behaviour and friction coefficient of pure nickel and $\mathrm{Ni}-\mathrm{SiC}$ nanostructured composite coatings as a function of rotating speed in a neutral $0.5 \mathrm{~mol} \mathrm{dm}^{-3} \mathrm{Na}_{2} \mathrm{SO}_{4}$ media [146]. The composite coating afforded lower corrosion rates, lower friction coefficient and higher polarisation resistance in comparison to a nickel coating.

\section{Modified RCEs}

Several modified RCEs have been considered for specialised corrosion studies, including scraped-, stepped-, bi-, micro- and 3D-electrodes. Deliberately non-uniform potential, current and concentration distributions in controlled turbulent flow around modified RCEs were considered in section 4 .

A combined rotating disc electrode and rotating cylinder electrode on a common rotating shaft is capable of providing independent laminar (RDE) and turbulent (RCE) mass transport data over a wide range of rotational speeds. Such a hybrid (CRODACE) nickel electrode in Figure 4c) has been used to quantify reduction of ferricyanide, i.e., hexacyanoferrate(II) ion and oxygen reduction by the authors [147]. 
The bimetallic rotating cylinder electrode (BRCE) has proved useful in galvanic corrosion rate measurements. Mansfeld [148] first reported its use for the measurement of galvanic currents for the corrosion of copper/aluminium alloy UNS A96061 in $3.5 \% \mathrm{NaCl}$, as a function of electrode velocity (200 to $600 \mu \mathrm{A} \mathrm{cm} \mathrm{cm}^{-2}$ over a rotation range of 150 to $955 \mathrm{rev} \mathrm{min}^{-1}$ ). The galvanic currents displayed a linear dependence on of flow velocity. Afterwards, Mansfeld and Kenkel determined the marine corrosion behaviour of stainless steel [149] and UNS A16061 aluminium alloys [150] galvanically coupled to stainless steel, copper and a range of aluminium alloys.

Kear et al. used a BRCE to study the corrosion behaviour of copper/nickel aluminium bronze and 90-10 copper-nickel/nickel aluminium bronze galvanic couples in filtered seawater media [114]. The authors used RCEs of diameter $2.0 \mathrm{~cm}$, length $1.6 \mathrm{~cm}$ and area $10.05 \mathrm{~cm}^{2}$, electrically insulated on a common shaft by $2 \mathrm{~mm}$ thick polytetrafluoethylene spacers. The electrochemistry of the galvanic electrode reactions under flow control was examined using zero resistance ammetry, corrosion potential measurements and a potential step current transient method. The galvanic corrosion potential and corrosion rate depended on the Reynolds number. The variability of oxygen mass transport rates under bimetallic impressed current cathodic protection (ICCP) was measured for a series of protection potentials and electrode rotation speeds. The measured bimetallic ICCP current was consistent to single-metal rotating cylinder electrode measurements. Figure 15a) shows the free corrosion and bimetallic corrosion potential transients for the $90-10 \mathrm{Cu}-\mathrm{Ni} / \mathrm{NAB}$ couple. The single metals were connected at $900 \mathrm{~s}$ and after an resting time of $100 \mathrm{~s}$, the rotation was started, followed by rate steps every $50 \mathrm{~s}$. Corrosion potential transients for the single metals were indistinguishable from those measured individually at rotating electrodes. At $200 \mathrm{rev} \mathrm{min}^{-1}$, the potentials of $\mathrm{Cu}$, $\mathrm{Cu}-\mathrm{Ni}$ and NAB were $-0.296,-0.263$ and $-0.301 \mathrm{~V} v s$. SCE, respectively. Figure $15 \mathrm{~b}$ ) presents 
linear relationships between logarithmic current density and logarithmic angular velocity for each value of applied potential in $37 \mathrm{mV}$ increments from -0.478 to $-0.590 \mathrm{~V} v s$. SCE. This implies that the cathodic component of the bimetallic electrode can be protected. The controlled reduction of oxygen was subject to a mixed and mass transport control, as shown by the increase of the slope value at more negative potentials.

Fluid flow can play a significant role in calcareous scale deposition and should be considered in any corrosion prediction model in the presence of scale. Quddus and Al-Hadhrami [73] used an RCE to control scale formation under turbulent flow conditions around an RCE. Scale formation was diffusion controlled and its deposition rate varied as $\mathrm{Re}^{0.5}$. A diversity of $\mathrm{CaCO}_{3}$ and $\mathrm{CaSO}_{4}$ crystal structures was observed in the films.

A sophisticated, multi-electrode BRCE has been described for weld corrosion of metals in brine following studies at Cranfield University [151,152]. The RCE arrangement allowed to couple galvanically the weld metal, heat affected zone (HAZ) and parent material in mutually insulated cylindrical electrodes and to subject them to high shear stresses. A zero-resistance ammeter was used to record the galvanic currents produced by the contact between the weld regions. The corrosion rates of each material were also evaluated from linear polarization resistance measurements.

Controlled fluid flow enhancement of mass transport rates to an RCE have included jet flow of electrolyte [25] and ultrasonication [79]. The importance of earlier studies is emphasised; for example, mass transport enhancement by jet flow to copper deposition at reticulated vitreous carbon foam RCEs was quantified by Nahlé, Reade and Walsh [25] while a uniform, triple 120 degree, face-on $25 \mathrm{kHz}$ ultrasonic probe geometry around a smooth RCE was examined by 
Gould and Walsh [79]. Despite many corrosion and electrodeposition studies on jet impingement to static electrodes, the application of jet flow to a corroding RCE does not appear to have received much attention. Such an electrode/flow geometry deserves study due to control of local shear stress as well as bulk convective-diffusion mass transport.

\section{Conclusions}

1. The RCE is not as well-known as the RDE for controlled-flow electrochemical studies. The smooth RDE is relatively easy to polish and has an analytical solution to fluid flow and mass transport but is usually restricted to small diameters and laminar flow. In contrast, the RCE normally operates in turbulent flow, has well proven, empirical mass transport expressions and offers a substantial circumferential surface with minimal edge effects.

2. Compared to wall jet electrodes and static electrodes in channel flow, no pumped electrolyte flow circuit is needed and the RCE provides effective mixing in a circular cross-sectional vessel, such as a beaker or polymeric tube.

3. Controlled turbulent flow and mass transport is accessible being characterised by peripheral velocity, $U$ and the dimensionless group, $R e$ in the case of flow and mass transport coefficient, $k_{m}$ and Sherwood number, Sh in the case of mass transport rates.

4. Important flow affected reactions under turbulent conditions in corrosion include metal dissolution, oxygen reduction, the stability of surface oxide films and the porosity of protective coatings.

5. The diversity of use for the RCE is indicated by subject area (including cathodic protection, corrosion inhibitors and protective coatings).

6. Corrosion studies not as common as electrodeposition ones at the RCE. 
7. An important use of the RCE is simulation of electrolyte velocity effects using a compact apparatus without the complications of a pumped flow circuit.

8. Single, hydrodynamically smooth electrode studies enhanced by many modifications to the electrode and geometry, including multiple RCEs under individual potential control on a common rotational axis, deliberately roughened surfaces and stepped RCEs as well as macro/micro electrode hybrids.

9. Jet impingement to RCE surfaces deserves study due to control of local shear stress as well as bulk convective-diffusion mass transport.

10. In comparison to the smooth RDE (where analytical solutions to fluid flow and mass transport are available) empirical RCE mass transport studies have given rise to a wide variety of constants and velocity exponents in mass transport controlled corrosion in turbulent flow. This is attributable to the diverse electrode surface preparation and cell geometry used by numerous workers together with poor temperature control in some cases.

\section{Aspects deserving further $R \& D$}

The following aspects of science and engineering merit further attention in continuing RCE development:

1. Practical multiphase (gas-liquid, solid-liquid, liquid-liquid or colloidal) electrolyte trials, including the importance of surfactants and phase transfer reagents.

2. Comprehensive nanofluid studies involving diverse combinations of gas-liquid or solidliquid electrolytes, dimple-related texture having been considered in a recent review of surface texture and tribology [153]. 
4. Strategic bi-electrodes consisting of a microelectrode, which has a potential and current separately addressable to those of a surrounding macroelectrode.

5. Combined RDE and RCE electrodes on a common shaft for corrosion studies under simultaneous laminar and turbulent conditions, respectively.

6. Relative roles of charge and mass transfer to metal surfaces in the presence of porous and mixed inhibitor films could be quantitatively established in turbulent flow using the RCE.

7. More quantitative and controlled studies of the synergistic effects of erosion and corrosion in tribocorrosion using smooth and controlled texture RCEs.

8. Corrosion of finely divided metal surfaces, such as nanostructured powders under controlled surface, potential and rotation speed conditions.

9. Controlled current- and potential distribution cells for corrosion, analogous to the RCH cell for electrodeposition.

10. Quantitative, side-by-side comparisons of the RCE with other controlled flow geometries, such as the slurry pot, circular and rectangular channel flow and wall jet electrodes (static disc, $\mathrm{RDE}$ and RCE) would facilitate the appropriate choice of a given electrode geometry for flow corrosion trials.

11. Time-dependent studies of film and coating porosity, and the effects of electrolyte composition on scale formation at an RCE having a controlled initial texture.

12. Quantitative and time-dependent studies of wiped, scraped and scratched RCE surfaces under controlled load conditions to examine film and coatings stability under tribological corrosion. 
13. Time-dependent studies of biofouling in turbulent flow conditions, including the importance of mechanical surface disruption, using miniature rods for rapid laboratory trials relevant to marine or dental corrosion; such studies would complement rotating disc studies in laminar flow.

14. In all cases, it is essential that authors state adequate details of electrode construction, surface finish (including texture and roughness), dimensions, rotation speed, peripheral velocity (hence Re), electrolyte temperature and dissolved oxygen level.

\section{Acknowledgements}

FCW is grateful to Ir K. Helle (AKZO Research bv) and Prof D.R. Gabe (Loughborough University) for their early introduction to rotating cylinders for corrosion and electrodeposition of metals. GK and FCW are grateful to Dr. K. Stokes for Dstl support and collaboration with Dr. B.D. Barker, during studies on copper and stainless steel alloys in seawater electrolytes. JAW and FCW gratefully acknowledge EPSRC support via a Green Tribology: Tribosmart surfaces and sensors research grant (EP/J001023/1) Platform Grant from Dec 2011 to Nov 2016. No new data were created during the preparation of this critical review. 


\section{References}

[1] R. Kelly, J. Scully, D. Shoesmith, R. Buchheit, Electrochemical Techniques in Corrosion Science and Engineering, Marcel Dekker, New York, 2003. doi:10.1201/9780203909133.

[2] R. Winston Revie (Ed.), Uhlig's Corrosion Handbook, 3rd ed., John Wiley \& Sons, Hoboken, N.J, 2011.

[3] S. Papavinasam, Corrosion Control in the Oil and Gas Industry, Gulf Professional Printing, 2014. doi:10.1016/C2011-0-04629-X.

[4] M. Eisenberg, C.W. Tobias, C.R. Wilke, Ionic mass transfer and concentration polarization at rotating electrodes, J. Electrochem. Soc. 101 (1954) 306-320. doi:10.1149/1.2781252.

[5] R. Kappesser, I. Cornet, R. Greif, Mass transfer to a rough rotating cylinder, J. Electrochem. Soc. 118 (1971) 1957-1959. doi:10.1149/1.2407875.

[6] D.R. Gabe, The rotating cylinder electrode, J. Appl. Electrochem. 4 (1974) 91-108. doi:10.1007/BF00609018.

[7] J.R. Selman, C.W. Tobias, Mass-transfer measurements by the limiting-current technique, in: Advances in Chemical Engineering Volume 10, Elsevier, 1978: pp. 211-318.

[8] D.R. Gabe, F.C. Walsh, The rotating cylinder electrode: A review of development, J. Appl. Electrochem. 13 (1983) 3-21. doi:10.1007/BF00615883.

[9] D.C. Silverman, Rotating cylinder electrode for velocity sensitivity testing, Corrosion. 40 (1984) 220-226. doi:10.5006/1.3581945.

[10] D.R. Gabe, G.D. Wilcox, J. González-García, F.C. Walsh, The rotating cylinder electrode: Its continued development and application, J. Appl. Electrochem. 28 (1998) 759-780. doi:10.1023/A:1003464415930.

[11] D.C. Silverman, The rotating cylinder electrode for examining velocity-sensitive corrosion-A review, Corrosion. 60 (2004) 1003-1023. doi:10.5006/1.3299215.

[12] G. Kear, B.D. Barker, K. Stokes, F.C. Walsh, Electrochemical corrosion behaviour of 90-10 Cu-Ni alloy in chloride-based electrolytes, J. Appl. Electrochem. 34 (2004) 659-669. doi:10.1023/B:JACH.0000031164.32520.58.

[13] G. Kear, B.D. Barker, K. Stokes, F.C. Walsh, Flow influenced electrochemical corrosion of nickel aluminium bronze - Part I. Cathodic polarisation, J. Appl. Electrochem. 34 (2004) 1235-1240.

[14] G. Kear, B.D. Barker, K. Stokes, F.C. Walsh, Flow influenced electrochemical corrosion of nickel aluminium bronze - Part II. Anodic polarisation and derivation of the mixed potential, J. Appl. Electrochem. 34 (2004) 1241-1248.

[15] G. Kear, C. Ponce de León, F.C. Walsh, Reduction of dissolved oxygen at a copper rotating disc electrode, Chemical Engineering Education. 39 (2005) 14-21. 
[16] C.T.J. Low, C. Ponce de León, F.C. Walsh, The rotating cylinder electrode (RCE) and its application to the electrodeposition of metals, Aust. J. Chem. 58 (2005) 246-262. doi:10.1071/CH05034.

[17] A.M. Rashidi, M. Packnezhad, M. Moshrefi-Torbati, F.C. Walsh, Erosioncorrosion synergism in an alumina/sea water nanofluid, Microfluid Nanofluid. 17 (2013) 225-232. doi:10.1007/s10404-013-1282-x.

[18] M. Eisenberg, C.W. Tobias, C.R. Wilke, Mass transfer at rotating cylinders, Chem. Engng Prog. Symp. Ser, 1955.

[19] D.C. Silverman, Rotating cylinder electrode - Geometry relationships for prediction of velocity-sensitive corrosion, Corrosion. 44 (1988) 42-49. doi:10.5006/1.3582024.

[20] B. Poulson, Advances in understanding hydrodynamic effects on corrosion, Corrosion Science. 35 (1993) 655-665. doi:10.1016/0010-938X(93)90201-Q.

[21] G. Kear, B.D. Barker, F.C. Walsh, Electrochemical corrosion of unalloyed copper in chloride media-A critical review, Corrosion Science. 46 (2004) 109-135. doi:10.1016/S0010-938X(02)00257-3.

[22] K.-S. Yang, J.-Y. Hwang, K. Bremhorst, S. Nesic, Turbulent flow around a rotating stepped cylinder, Phys. Fluids. 14 (2002) 1544. doi:10.1063/1.1455625.

[23] G. Kear, S.-H. Huang, K. Bremhorst, A. Purchase, Determination of diffusion controlled reaction rates at a solid/liquid interface using scanning electron microscopy, J Microsc. 226 (2007) 218-229. doi:10.1111/j.13652818.2007.01774.x.

[24] K.D. Efird, E.J. Wright, J.A. Boros, T.G. Hailey, Correlation of steel corrosion in pipe flow with jet impingement and rotating cylinder tests, Corrosion. 49 (1993) 992-1003. doi:10.5006/1.3316026.

[25] A.H. Nahlé, G.W. Reade, F.C. Walsh, Mass transport to reticulated vitreous carbon rotating cylinder electrodes, J. Appl. Electrochem. 25 (1995) 450-455. doi:10.1007/BF00260687.

[26] A. Neville, C. Wang, inhibitor performance on corrosion and erosion/corrosion under turbulent flow with sand and $\mathrm{CO}_{2}-\mathrm{An} \mathrm{AC}$ impedance study, SPE Production \& Operations. 23 (2008) 215-220. doi:10.2118/100441-PA.

[27] American Water Works Association Research Foundation, Water quality monitoring - metal release in closed loop systems, in: Internal Corrosion, 2nd ed., DVGW - TEW (Technologie Zentrum Wasser), Denver, USA, 1996: pp. 469-475.

[28] A.R. Alonso, G.T. Lapidus, I. González, Selective silver electroseparation from ammoniacal thiosulfate leaching solutions using a rotating cylinder electrode reactor (RCE), Hydrometallurgy. 92 (2008) 115-123. doi:10.1016/j.hydromet.2008.02.001.

[29] J.P. Fornés, G.A. González, J.M. Bisang, Electrochemical conversion of sulfur dioxide with a rotating cylinder electrode working as anode or cathode, J. Chem. Technol. Biotechnol. 91 (2016) 219-225. doi:10.1002/jctb.4567. 
[30] F.J. Almazán-Ruiz, F. Caballero, M.R. Cruz-Díaz, E.P. Rivero, J. Vazquez-Arenas, I. González, Nickel recovery from an electroplating rinsing effluent using RCE bench scale and RCE pilot plant reactors: The influence of $\mathrm{pH}$ control, Trans. IChemE. 97 (2015) 18-27.

[31] A.H. Sulaymon, B.A. Abdulmajeed, A.B. Salman, Electrochemical removal of cadmium from simulated wastewater using a smooth rotating cylinder electrode, Desalination and Water Treatment. 54 (2015) 2557-2563.

doi:10.1080/19443994.2014.903520.

[32] O. González Pérez, J.M. Bisang, Electrochemical synthesis of hydrogen peroxide with a three-dimensional rotating cylinder electrode, J. Chem. Technol. Biotechnol. 89 (2013) 528-535. doi:10.1002/jctb.4149.

[33] A.M. Nor, The effect of turbulent flow on corrosion of mild steel in high partial $\mathrm{CO}_{2}$ environments, $\mathrm{PhD}$ thesis, Russ College of Engineering \& Technology of Ohio University, USA, 2013.

[34] D. Rappleye, M.F. Simpson, Application of the rotating cylinder electrode in molten LiCl-KCl eutectic containing uranium(III)- and magnesium(II)-chloride, Journal of Nuclear Materials. 487 (2017) 362-372.

doi:10.1016/j.jnucmat.2017.02.037.

[35] G. Kear, Electrochemical corrosion of marine alloys under flowing conditions, $\mathrm{PhD}$ thesis, University of Portsmouth, UK, 2001.

[36] T.Y. Chen, A.A. Moccari, D.D. Macdonald, Development of controlled hydrodynamic techniques for corrosion testing, Corrosion. 48 (1992) 239-255. doi:10.5006/1.3315930.

[37] Y.T. Al-Janabi, A.L. Lewis II, High speed corrosion-resistant rotating cylinder electrode system, US Patent 2,621,263 B, 2003.

[38] F.C. Walsh, C. Ponce de León, A review of the electrodeposition of metal matrix composite coatings by inclusion of particles in a metal layer: An established and diversifying technology, Trans. Inst. Met. Finish. 92 (2014) 83-98. doi:10.1179/0020296713Z.000000000161.

[39] F.C. Walsh, The role of the rotating cylinder electrode reactor in metal ion removal, in: D. Gernders, N. Weinberg (Eds.), Electrochemistry for a Cleaner Environment, The Electrosynthesis Company, New York, 1992: pp. 101-159.

[40] F.C. Walsh, N.A. Gardner, D.R. Gabe, Development of the Eco-Cascade cell reactor, J. Appl. Electrochem. 12 (1982) 299-309.

[41] F.C. Walsh, A First Course in Electrochemical Engineering, The Electrochemical Consultancy, Romsey, 1993.

[42] A.M. Couper, D. Pletcher, F.C. Walsh, Electrode materials for electrosynthesis, Chem. Rev. 90 (1990) 837-865. doi:10.1021/cr00103a010.

[43] F.C. Walsh, D.R. Gabe, Controlled-potential electrodeposition of metals at a rotating cylinder electrode (the Eco-Cell), Surface Technology. 12 (1981) 25-37. 
[44] F.C. Walsh, Unpublished work with C. Gould, in: Electrodeposition of Metals in a Rotating Cylinder Electrode Reactor, 1981.

[45] E.P. Rivero, P. Granados, F.F. Rivera, M. Cruz, Mass transfer modelling and simulation at a rotating cylinder electrode (RCE) reactor under turbulent flow for copper recovery, Chem. Eng. Sci. 65 (2010) 3042-3049.

[46] F.F. Rivera, J.L. Nava, Mass transport studies at rotating cylinder electrode (RCE): Influence of using plates and concentric cylinder as counter electrodes, Electrochim. Acta. 52 (2007) 5868-5872. doi:10.1016/j.electacta.2007.03.014.

[47] C.T.J. Low, E.P.L. Roberts, F.C. Walsh, Numerical simulation of the current, potential and concentration distributions along the cathode of a rotating cylinder Hull cell, Electrochim. Acta. 52 (2007) 3831-3840. doi:10.1016/j.electacta.2006.10.056.

[48] S. Nesic, F. Carroll, Horizontal rotating cylinder-A compact apparatus for studying the effect of water wetting on carbon dioxide corrosion of mild steel, Corrosion. 59 (2012) 1085-1095. doi:10.5006/1.3277528.

[49] ASTM G184-06(2016), Standard practice for evaluating and qualifying oil field and refinery corrosion inhibitors using rotating cage, ASTM International, West Conshohocken, PA, USA, 2016.

[50] Y. Alvarado Medina, S. Serna Barquera, J.C. García Castrejón, J.R. Romero, Simulation of the hydrodynamic conditions of a rotating cage for evaluating corrosion inhibitors, IJCER. 6 (2016) 6-9.

[51] Pine Research Instrumentation, Pine Research Instrumentation Technical Note 2006-01, Study of mass-transport limited corrosion using Pine rotated cylinder electrodes. An overview of theory and practice, 5908 Triangle Drive, Raleigh, N.C. 27617. USA, 2006.

[52] Gamry Instruments, RDE 710 Instruction manual, 734 Louis Drive, Warminster, PA 18974, USA, 2011.

[53] ASTM G170-06 (2012), Standard practice for evaluating and qualifying oil field and refinery corrosion inhibitors in the laboratory, ASTM International, West Conshohocken, PA, USA, 2012.

[54] ASTM G185-06 (2012), Standard practice for evaluating and qualifying oil field and refinery corrosion inhibitors using the rotating cylinder electrode, ASTM International, West Conshohocken, PA, USA, 2012.

[55] D.R. Gabe, D.J. Robinson, Mass transfer in a rotating cylinder cell-I. Laminar flow, Electrochim. Acta. 17 (1972) 1121-1127. doi:10.1016/0013-4686(72)90028$\mathrm{X}$.

[56] B. Morrison, K. Striebel, P.N. Ross Jr., P.C. Andricacos, Kinetic studies using a rotating cylinder electrode: Part I. Electron transfer rates in ferrous/ferric sulfate on platinum, J. Electroanal. Chemistry Interfacial Electrochem. 215 (1986) 151-160. doi:10.1016/0022-0728(86)87012-7.

[57] D.R. Gabe, P.A. Makanjuola, Enhanced mass transfer using roughened rotating 
cylinder electrodes in turbulent flow, J. Appl. Electrochem. 17 (1987) 370-384.

[58] G. Kreysa, Elektrochemie mit dreidimensionalen Elektroden, Chemie Ingenieur Technik. 55 (1983) 23-30. doi:10.1002/cite.330550108.

[59] J.M. Grau, J.M. Bisang, Mass transfer studies at rotating cylinder electrodes of expanded metal, J. Appl. Electrochem. 35 (2005) 285-291.

[60] F.S. Holland, National Research Development Corp UK, Method of producing metal powder, US Patent 4,028,199, 1977.

[61] N.A. Gardner, F.C. Walsh, The design and application of rotating cylinder electrode technology to continuous production of metal, in: Electrochemical Cell Design, Springer US, Boston, MA, 1984: pp. 225-258. doi:10.1007/978-1-46132795-0 12.

[62] D.R. Gabe, F.C. Walsh, Recovery of metal from industrial process liquors using a rotating cylinder electrode reactor, I. Chem. Symp. Ser. 116 (1990) 219-229.

[63] A.C. Makrides, N. Hackerman, Dissolution of metals in aqueous acid solutions II. Depolarized dissolution of mild steel, J. Electrochem. Soc. 105 (1958) 156-162. doi:10.1149/1.2428782.

[64] B. Poulson, Mass transfer from rough surfaces, Corrosion Science. 30 (1990) 743746. doi:10.1016/0010-938X(90)90037-6.

[65] A. Eklund, D. Simonsson, Enhanced mass transfer to a rotating cylinder electrode with axial flow, J. Appl. Electrochem. 18 (1988) 710-714.

doi:10.1007/BF01016897.

[66] P.A. Makanjuola, D.R. Gabe, Mass transfer at rough surfaces: reconsideration of data reported by Sedahmed et al, J. Appl. Electrochem. 17 (1987) 434-436.

[67] D.P. Barkey, R.H. Muller, C.W. Tobias, Roughness development in metal electrodeposition I. Experimental results, J. Electrochem. Soc. 136 (1989) 21992207. doi:10.1149/1.2097258.

[68] D.P. Barkey, R.H. Muller, C.W. Tobias, Roughness development in metal electrodeposition II. Stability theory, J. Electrochem. Soc. 136 (1989) 2207-2214. doi:10.1149/1.2097260.

[69] D.R. Gabe, F.C. Walsh, Enhanced mass transfer at the rotating cylinder electrode. I. Characterization of a smooth cylinder and roughness development in solutions of constant concentration, J. Appl. Electrochem. 14 (1984) 555-564. doi:10.1007/BF00626299.

[70] D.R. Gabe, F.C. Walsh, Enhanced mass transfer at the rotating cylinder electrode. II. Development of roughness for solutions of decreasing concentration, J. Appl. Electrochem. 14 (1984) 565-572.

[71] D.R. Gabe, D.J. Robinson, Mass transfer in a rotating cylinder cell-II. turbulent flow, Electrochim. Acta. 17 (1972) 1129-1137.

[72] R.A. Holser, G. Prentice, R.B. Pond Jr., R. Guanti, Use of rotating cylinder 
electrodes to simulate turbulent flow conditions in corroding systems, Corrosion. 46 (1990) 764-769.

[73] A. Quddus, L.M. Al-Hadhrami, Hydrodynamically deposited $\mathrm{CaCO}_{3}$ and $\mathrm{CaSO}_{4}$ scales, Desalination. 246 (2009) 526-533. doi:10.1016/j.desal.2008.11.005.

[74] D.R. Gabe, F.C. Walsh, Enhanced mass transfer at the rotating cylinder electrode: III. Pilot and production plant experience, J. Appl. Electrochem. 15 (1985) 807824. doi:10.1007/BF00614358.

[75] P.C. Singh, P. Mishra, Mass transfer to newtonian and non-newtonian fluids from rotating cylinders, Chem. Eng. Sci. 35 (1980) 1657-1666. doi:10.1016/00092509(80)80058-3.

[76] A. Meštrović-Markovinović, D. Matić, Mass transfer to a rotating horizontal cylinder electrode with full and partial immersion, J. Appl. Electrochem. 14 (1984) 675-678. doi:10.1007/BF00626312.

[77] D.R. Gabe, F.C. Walsh, Removal of cadmium from a zinc calcine liquor by means of a rotating cylinder electrode reactor, in: The Reinhardt Schuhmann Symposium on Innovative Technology and Reactor Design in Extraction Metallurgy, 1986: pp. $775-794$.

[78] D. Robinson, F.C. Walsh, The performance of a 500 A rotating cylinder electrode reactor. Part 1: Current-potential data and single pass studies, Hydrometallurgy. 26 (1991) 93-114. doi:10.1016/0304-386X(91)90024-G.

[79] F.C. Walsh, Electrodeposition of metals in a rotating cylinder electrode reactor, $\mathrm{PhD}$ thesis, University of Loughborough, 1981.

[80] A.F.S. Afshar, D.R. Gabe, B. Sewell, Mass transfer at rotating cone electrodes, J. Appl. Electrochem. 21 (1991) 32-39.

[81] C. Madore, A.C. West, M. Matlosz, D. Landolt, Design considerations for a cylindrical hull cell with forced convection, Electrochim. Acta. 37 (1992) 69-74. doi:10.1016/0013-4686(92)80013-C.

[82] C. Madore, M. Matlosz, D. Landolt, Experimental investigation of the primary and secondary current distribution in a rotating cylinder Hull cell, J. Appl. Electrochem. 22 (1992) 1155-1160. doi:10.1007/BF01297417.

[83] C. Madore, C. Landolt, C. HaBenprug, J.A. Hermann, Application of the rotating cylinder Hull cell to the measurement of throwing power and the monitoring of copper plating baths, Plat. Surf. Finish. (1995) 36-41.

[84] C.T.J. Low, F.C. Walsh, Electrodeposition of tin, copper and tin-copper alloys from a methanesulfonic acid electrolyte containing a perfluorinated cationic surfactant, Surf. Coat. Technol. 202 (2008) 1339-1349.

doi:10.1016/j.surfcoat.2007.06.032.

[85] D.C. Silverman, M.E. Zerr, Application of the rotating cylinder electrode-E-Brite 26-1/concentrated sulfuric acid, Http://Dx.Doi.org/10.5006/1.3583034. 42 (1986) 633-640. doi:10.5006/1.3583034. 
[86] Q. Lu, M.M. Stack, C.R. Wiseman, AC impedance spectroscopy as a technique for investigating corrosion of iron in hot flowing Bayer liquors, J. Appl. Electrochem. 31 (2001) 1373-1379. doi:10.1023/A:1013824010279.

[87] D.C. Silverman, Corrosion prediction in complex environments using electrochemical impedance spectroscopy, Electrochim. Acta. 38 (1993) 2075-2078. doi:10.1016/0013-4686(93)80342-W.

[88] R. Galván-Martínez, D. Cabrera-de la Cruz, A. Contreras, R. Orozco-Cruz, A novel experimental arrangement for corrosion study of X60 pipeline steel weldments at turbulent flow conditions, Corrosion Engineering, Science and Technology. 51 (2016) 400-407. doi:10.1080/1478422X.2015.1124598.

[89] T. Dabros, J.C. Donini, W.I. Friesen, K. Kar, R.W. Revie, Predictive tests for internal pipeline corrosion, in: 8th European Symposium on Corrosion Inhibitors, 1995: pp. 1125-1134.

[90] P. Altoe, G. Pimenta, C.F. Moulin, S.L. Diaz, O.R. Mattos, Evaluation of oilfield corrosion inhibitors in $\mathrm{CO}_{2}$ containing media: a kinetic study, Electrochim. Acta. 41 (1996) 1165-1172. doi:10.1016/0013-4686(95)00467-X.

[91] A. Mekki, S. Turgoose, Effect of Particulate Impact on Oilfield Inhibitor, in: International Corrosion Congress: Frontiers in Corrosion Science and Technology, Granada, Spain. Sept. 22-27, 2002: pp. 576/1-576/9.

[92] S. Papavinasam, R.W. Revie, M. Attard, A. Demoz, Comparison of laboratory methodologies to evaluate corrosion inhibitors for oil and gas pipelines, Corrosion. 59 (2003) 897-912. doi:10.5006/1.3287711.

[93] D. Martínez, R. Gonzalez, K. Montemayor, A. Juarez-Hernandez, G. Fajardo, M.A.L. Hernandez-Rodriguez, Amine type inhibitor effect on corrosion-erosion wear in oil gas pipes, Wear. 267 (2009) 255-258.

[94] S.M. Yaakob, M.C. Ismail, Corrosion inhibitor performance with presence of $\mathrm{FeCO}_{3}$ film in $\mathrm{CO}_{2}$ corrosion environment under fluid flow effect, Adv. Mat. Res. 789 (2013) 507-510. doi:10.4028/www.scientific.net/AMR.789.507.

[95] O.O. Ige, R. Barker, X. Hu, L.E. Umoru, A. Neville, Assessing the influence of shear stress and particle impingement on inhibitor efficiency through the application of in-situ electrochemistry in a $\mathrm{CO}_{2}$-saturated environment, Wear. 304 (2013) 49-59.

[96] L.D. Paolinelli, B. Brown, S.N. Simison, S. Nesic, Inhibition of $\mathrm{CO}_{2}$ corrosion of carbon steel with 1\% Cr, Materials Chemistry and Physics. 136 (2012) 1092-1102. doi:10.1016/j.matchemphys.2012.08.055.

[97] R. Galván-Martínez, R. Orozco-Cruz, R. Torres Sanchez, E.A. Martinez, Corrosion study of the X52 steel immersed in seawater with a corrosion inhibitor using a rotating cylinder electrode, Materials and Corrosion. 61 (2010) 872-876. doi:10.1002/maco.200905441.

[98] J. Carew, A. Al-Hashem, A. Al-Sayegh, Flow effects on the corrosion inhibition of seawater injection system, Proc. Corrosion \& Prevention-98, 23-25th November, 
Hobari, Australia (1998), paper 038, 193-197.

[99] R. Olalde, J. Genesca, Effect of flow and a triazole derivative based inhibitor on the corrosion of API X52 pipeline steel grade in $\mathrm{CO}_{2}$ saturated brine solution, ECS Trans. 20 (2009) 529-541.

[100] D. Liu, Y.B. Qiu, Y. Tomoe, K. Bando, X.P. Guo, Interaction of inhibitors with corrosion scale formed on $\mathrm{N} 80$ steel in $\mathrm{CO}_{2}$-saturated $\mathrm{NaCl}$ solution, Materials and Corrosion. 62 (2011) 1153-1158. doi:10.1002/maco.201106075.

[101] A. Rustandi, J.W. Soedarsono, B. Suharno, The use of mixture of piper betle and green tea as a green corrosion inhibitor for API X-52 Steel in aerated 3.5\% NaCl solution at various rotation rates, Adv. Mat. Res. 383-390 (2012) 5418-5425. doi:10.4028/www.scientific.net/AMR.383-390.5418.

[102] R. Galván-Martínez, R. Orozco-Cruz, R. Torres Sanchez, E.A. Martínez-Martinez, Characterization of the corrosion kinetic of X52 steel in seawater with biocides, MRS Online Proceedings Library Archive. 1242 (2009) S4-46. doi:10.1557/PROC-1242-S4-46.

[103] J.N. Connor, A. Xavier, L. Voss, D.M. Druskovich, Screening of green inhibitors used during acid cleaning of heat exchanger tubes in the alumina industry, in: Corrosion and Prevention Always Protecting, Always Learning, 14th to 17th November, Adelaide, Australia, 2010: pp. 1-11.

[104] D.J. Kalota, D.C. Silverman, Behavior of aspartic acid as a corrosion inhibitor for steel, Corrosion. 50 (1994) 138-145. doi:10.5006/1.3293502.

[105] Y. Liu, Y.F. Cheng, Inhibiting effect of cerium ions on corrosion of 3003 aluminum alloy in ethylene glycol-water solutions, J. Appl. Electrochem. 41 (2011) 383-388.

[106] J.M. Maciel, S.M.L. Agostinho, Use of a rotating cylinder electrode in corrosion studies of a 90/10 $\mathrm{Cu}-\mathrm{Ni}$ alloy in $0.5 \mathrm{~mol} \mathrm{~L}^{-1} \mathrm{H}_{2} \mathrm{SO}_{4}$ media, J. Appl. Electrochem. 30 (2000) 981-985.

[107] A.Y. Musa, A. Kadhum, A.B. Mohamad, Stability of layer forming for corrosion inhibitor on mild steel surface under hydrodynamic conditions, Int. J. Electrochem. Sci. 4 (2009) 707-716.

[108] F. Mansfeld, M.W. Kendig, S. Tsai, Corrosion kinetics in low conductivity media-I. Iron in natural waters, Corrosion Science. 22 (1982) 455-471.

[109] B. Kinsella, Y.J. Tan, S. Bailey, The application of electrochemical techniques and cylinder electrodes in the study of inhibitor film persistency, ACA 1995: Corrosion and Prevention 95: Proceedings of the Australasian Corrosion Association Conference, Perth, Australia, Nov. 12-16 (1995), Paper 54.

[110] B. Heeg, T. Moros, D. Klenerman, Persistency of corrosion inhibitor films on csteel under multiphase flow conditions. Part i: the jet-cylinder arrangement, Corrosion Science. 40 (1998) 1303-1311. doi:10.1016/S0010-938X(98)00012-2.

[111] B. Heeg, D. Klenerman, Persistency of corrosion inhibitor films on C-steel under 
multiphase flow conditions. Part ii: optical SHG and electrochemical studies, Corrosion Science. 40 (1998) 1313-1329.

[112] S.B. Kichenko, A.B. Kichenko, Research of steel corrosion rate and stability of corrosion inhibitor film using the rotating cylinder, Praktika Protivokorrozionnoi Zashchity. 4 (2008) 24-34.

[113] B. Evgeny, T. Hughes, D. Eskin, Effect of surface roughness on corrosion behaviour of low carbon steel in inhibited 4M hydrochloric acid under laminar and turbulent flow conditions, Corrosion Science. 103 (2016) 196-205. doi:10.1016/j.corsci.2015.11.019.

[114] G. Kear, B.D. Barker, K.R. Stokes, F.C. Walsh, Corrosion and impressed current cathodic protection of copper-based materials using a bimetallic rotating cylinder electrode (BRCE), Corrosion Science. 47 (2005) 1694-1705. doi:10.1016/j.corsci.2004.08.013.

[115] M. Rosales, T. Pérez, J.L. Nava, Computational fluid dynamic simulations of turbulent flow in a rotating cylinder electrode reactor in continuous mode of operation, Electrochim. Acta. 194 (2016) 338-345.

[116] P. Atempa-Rosiles, M. Diáz-Cruz, Simulation of turbulent flow of a rotating cylinder electrode and evaluation of its effect on the surface of steel API 5L X-56 during the rate of corrosion in brine added with kerosene and $\mathrm{H}_{2} \mathrm{~S}$, Int. J. Electrochem. Sci. 9 (2014) 4805-4815.

[117] R. Galván-Martínez, R. Orozco-Cruz, J. Mendoza-Flores, A. Contreras, J. Genesca, Study of the mass transport on corrosion of low carbon steel immersed in sour solution under turbulent flow conditions, in: H. Schulz (Ed.), Hydrodynamics Optimizing Methods and Tools, Intech Publishers, 2011: pp. 353-372.

[118] S.S. Rajahram, T.J. Harvey, R.J.K. Wood, Erosion-corrosion resistance of engineering materials in various test conditions, Wear. 267 (2009) 244-254. doi:10.1016/j.wear.2009.01.052.

[119] L.N. Bengoa, W.R. Tuckart, N. Zabala, G. Prieto, W.A. Egli, Bronze electrodeposition from an acidic non-cyanide high efficiency electrolyte: Tribological behavior, Surf. Coat. Technol. 253 (2014) 241-248. doi:10.1016/j.surfcoat.2014.05.046.

[120] S.A. Silkin, A.V. Gotelyak, N.I. Tsyntsaru, A.I. Dikusar, Size effect of microhardness of nanocrystalline Co-W coatings produced from citrate and gluconate solutions, Surf. Engin. Appl.Electrochem. 51 (2015) 228-234.

[121] S. Nesic, J. Bienkowski, K. Bremhorst, K.S. Yang, Testing for erosion-corrosion under disturbed flow conditions using a rotating cylinder with a stepped surface, Corrosion. 56 (2000) 1005-1014. doi:10.5006/1.3294377.

[122] S. Nesic, G.T. Solvi, S. Skjerve, Comparison of rotating cylinder and loop methods for testing $\mathrm{CO}_{2}$ corrosion inhibitors, Br. Corros. J. 32 (1997) 269-276. doi:10.1179/000705997798129188.

[123] Q.-L. Yuan, M.M. Stack, Effect of preferential dissolution on erosion-corrosion for 
chromium steel in alkali slurry, Trans. Nonferrous Metal Soc. China. 12 (2002) 931-935.

[124] Y. Chen, H.J. Chen, W.P. Jepson, Effects of multiphase flow on corrosion inhibitor, Corrosion 99. (1999) Paper 12.

[125] L. Labraga, N. Bourabaa, T. Berkah, Wall shear stress from a rotating cylinder in cross flow using the electrochemical technique, Exp. Fluids. 33 (2002) 488-496.

[126] Y.P. Asmara, Y.C. Wei, M.F. Ismail, Flow assisted erosion-corrosion of high speed steel (HSS) in nanofluid coolant, Applied Mechanics \& Materials. 695 (2015) 143146.

[127] C.T.J. Low, R.G.A. Wills, F.C. Walsh, Electrodeposition of composite coatings containing nanoparticles in a metal deposit, Surf. Coat. Technol. 201 (2006) 371383.

[128] L.D. Paolinelli, G.E. Carr, Mechanical integrity of corrosion product films on rotating cylinder specimens, Corrosion Science. 92 (2015) 155-161. doi:10.1016/j.corsci.2014.11.042.

[129] N. Jegadeeswaran, M.R. Ramesh, K.U. Bhat, Combating corrosion degradation of turbine materials using HVOF sprayed $25 \%\left(\mathrm{Cr}_{3} \mathrm{C}_{2}-25(\mathrm{Ni} 20 \mathrm{Cr})\right)+\mathrm{NiCrAlY}$ coating, International Journal of Corrosion. 2013 (2013) 1-11. doi: $10.1155 / 2013 / 824659$.

[130] S. Karthikeyan, G. Venkatachalam, S. Narayanan, K.N. Srinivasan, Characteristics of zinc- $\mathrm{Cr}_{2} \mathrm{O}_{3}$ composite coatings, Journal of Electroplating Finishing, China. 30 (2011) 12-15.

[131] B. Lee, Electrochemical corrosion testing of aluminum alloys coated with a thinfilm trivalent chromium coating, in: Abstracts, 40th Central Regional Meeting of the American Chemical Society, Columbus, OH, United States, June 10-14 (2008), CRM-166.

[132] H. Conrad, T. Golden, Improvement of zinc-nickel and copper-nickel corrosion resistant coatings through the incorporation of silicate nanocomposites, in: 67th Southwest Regional Meeting of the American Chemical Society, Austin, TX, USA, November 9-12 (2011), SWRM-186.

[133] U. Riaz, C. Nwaoha, S.M. Ashraf, Recent advances in corrosion protective composite coatings based on conducting polymers and natural resource derived polymers, Progress in Organic Coatings. 77 (2014) 743-756.

[134] K.G. Thompson, B.C. Benicewicz, Corrosion-protective coatings from electroactive polymers, in: P. Zarras, J.D. Stenger-Smith, Y. Wei (Eds.), Electroactive Polymers for Corrosion Control, 2003: pp. 18-33.

[135] N. Kouloumbi, G.M. Tsangaris, A. Skordos, P. Karkanas, I. Kyriopoulou, Performance of polymeric particulate composites as corrosion protective coatings of steel surfaces, Materials Science Forum. 192-194 (1995) 813-824. doi:10.4028/www.scientific.net/MSF.192-194.813.

[136] E. Husain, T.N. Narayanan, J.J. Taha-Tijerina, S. Vinod, R. Vajtai, P.M. Ajayan, 
Marine corrosion protective coatings of hexagonal boron nitride thin films on stainless steel, ACS Appl. Mater. Interfaces. 5 (2013) 4129-4135.

doi:10.1021/am400016y.

[137] S. Kirtay, Characterization of $\mathrm{SiO}_{2}-\mathrm{TiO}_{2}$ hybrid corrosion protective coatings on mild steel, J. Mater. Eng. Perform. 23 (2014) 4309-4315. doi:10.1007/s11665-0141218-y.

[138] A.K. Singh, S. Kaity, K. Singh, J. Thomas, T.R.G. Kutty, S. Sinha, Pulsed laser deposition of alumina coating for corrosion protection against liquid uranium, Materials Chemistry and Physics. 143 (2014) 1446-1451. doi:10.1016/j.matchemphys.2013.11.063.

[139] A.K. Singh, T.R.G. Kutty, S. Sinha, Pulsed laser deposition of corrosion protective yttrium oxide $\left(\mathrm{Y}_{2} \mathrm{O}_{3}\right)$ coating, Journal of Nuclear Materials. 420 (2012) 374-381. doi:10.1016/j.jnucmat.2011.10.028.

[140] S. Ershov, M.E. Druart, M. Poelman, D. Cossement, R. Snyders, M.G. Olivier, Deposition of cerium oxide thin films by reactive magnetron sputtering for the development of corrosion protective coatings, Corrosion Science. 75 (2013) 158168. doi:10.1016/j.corsci.2013.05.028.

[141] W. Fürbeth, H.-Q. Nguyen, M. Schütze, Novel corrosion protective coatings for aluminium alloys and steels based on oxidic nanoparticles, IJMR. 98 (2007) 589596. doi:10.3139/146.101506.

[142] M. Burriel, G. García, J. Santiso, A.N. Hansson, S. Linderoth, A. Figueras, $\mathrm{Co}_{3} \mathrm{O}_{4}$ protective coatings prepared by pulsed injection metal organic chemical vapour deposition, Thin Solid Films. 473 (2005) 98-103. doi:10.1016/j.tsf.2004.07.081.

[143] S.M. Zemskova, J.A. Haynes, T.M. Besmann, MOCVD of aluminosilicate corrosion protective coatings, in: CVD XV Proceedings of the Fifteenth International Symposium on Chemical Vapor Deposition, The Electrochemical Society, 2000: pp. 325-332.

[144] S.C. Sahu, A.K. Samantara, M. Seth, S. Parwaiz, B.P. Singh, P.C. Rath, B. K. Jena, A facile electrochemical approach for development of highly corrosion protective coatings using graphene nanosheets, Electrochem. Commun. 32 (2013) 22-26.

[145] R.L. Zeller III, Electrochemical corrosion testing of high phosphorus electroless nickel in 5\% NaCl, Corrosion. 47 (1991) 692-702. doi:10.5006/1.3585309.

[146] L. Benea, P.L. Bonora, A. Borello, S. Martelli, Wear corrosion properties of nanostructured $\mathrm{SiC}-$ nickel composite coatings obtained by electroplating, Wear. 249 (2001) 995-1003. doi:10.1016/S0043-1648(01)00844-4.

[147] S. Cleghorn, F.C. Walsh, Mass transport to a combined RDE and RCE (CRODACE) on a common shaft, unpublished.

[148] F. Mansfeld, Instrumentation for measurements of galvanic currents as a function of velocity of metal/electrolyte, Corrosion. 32 (1976) 380-382. doi:10.5006/00109312-32.9.380. 
[149] F. Mansfeld, J. Kenkel, Laboratory Studies of Galvanic Corrosion of Aluminum Alloys, in: Galvanic and Pitting Corrosion-Field and Laboratory Studies, ASTM International, 100 Barr Harbor Drive, PO Box C700, West Conshohocken, PA 19428-2959, 1976: pp. 20-47.

[150] F. Mansfeld, J.V. Kenkel, The effect of velocity on galvanic corrosion on Al alloys, Corrosion. 33 (1977) 376-382.

[151] K. Alawadhi, Inhibition of weld corrosion in flowing brines containing carbon dioxide, $\mathrm{PhD}$ thesis, University of Cranfield, UK, 2009.

[152] K. Alawadhi, M.J. Robinson, Preferential weld corrosion of X65 pipeline steel in flowing brines containing carbon dioxide, Corrosion Engineering, Science and Technology. 46 (2013) 318-329.

[153] D. Gropper, L. Wang, T.J. Harvey, Hydrodynamic lubrication of textured surfaces: A review of modeling techniques and key findings, Tribology International. 94 (2016) 509-529. 


\begin{tabular}{|c|c|}
\hline Requirements & Features of RCE \\
\hline Analysis of experimental data & $\begin{array}{l}\text { Uniform mass transport and established, } \\
\text { empirical mass transport correlation. }\end{array}$ \\
\hline Convenient and simple design & $\begin{array}{l}\text { Normally an inner rotating inner cylinder } \\
\text { electrode is used as the WE with a stationary } \\
\text { concentric outer cylinder as the CE. }\end{array}$ \\
\hline Well defined hydrodynamics & $\begin{array}{l}\text { Controlled agitation; turbulent flow is } \\
\text { established at low rotation speeds with } \\
\text { reproducible peripheral velocity and } \\
\text { concentration profiles. }\end{array}$ \\
\hline Controlled global and local reaction rates & $\begin{array}{l}\text { Potential and current distributions can be } \\
\text { uniform or deliberately non-uniform, } \\
\text { depending on the position and geometry of } \\
\text { the WE and CE. }\end{array}$ \\
\hline Enhanced mass transport & $\begin{array}{l}\text { The high mass transport can be improved by } \\
\text { roughened surfaces, ultrasound, expanded } \\
\text { meshes, jet electrolyte flow and 3- } \\
\text { dimensional porous materials. }\end{array}$ \\
\hline Versatility & $\begin{array}{l}\text { The RCE can have a smooth or rough } \\
\text { surface; it can be single electrode, bi- } \\
\text { electrode, multiple electrode or a } \\
\text { macro/microelectrode combination. }\end{array}$ \\
\hline
\end{tabular}

Table 1. Major features of the RCE for studies of corrosion and protection of metals. After Low et al. [16]. 


\begin{tabular}{|c|c|c|c|c|c|c|c|c|c|}
\hline & \multirow{2}{*}{$\begin{array}{l}\text { Type of RCE } \\
\text { surface }\end{array}$} & \multicolumn{3}{|c|}{ RCE characteristics } & \multirow{2}{*}{$\begin{array}{l}\mathrm{Re} \\
\text { range }\end{array}$} & \multirow[t]{2}{*}{ Mass transport correlation } & \multirow{2}{*}{$\begin{array}{l}\text { Electrode } \\
\text { reaction }\end{array}$} & \multirow[t]{2}{*}{ Authors } & \multirow[t]{2}{*}{ Ref. } \\
\hline & & $d / \mathrm{cm}$ & $l / \mathrm{cm}$ & $\begin{array}{l}\omega / \mathrm{rev} \\
\min ^{-1}\end{array}$ & & & & & \\
\hline $\mathrm{a}$ & $\begin{array}{l}\text { Hydrodynamically } \\
\text { smooth }\end{array}$ & $\begin{array}{l}1.98 \text { to } \\
5.98\end{array}$ & 15.11 & $\begin{array}{l}30 \text { to } \\
1,650\end{array}$ & $\begin{array}{l}210 \text { to } \\
240,000\end{array}$ & $S h=0.079 R e^{0.7} S c^{0.356}$ & $\begin{array}{l}\text { Ferricyanide } \\
\text { reduction }\end{array}$ & $\begin{array}{l}\text { Eisenberg, } \\
\text { Tobias \& } \\
\text { Wilke }\end{array}$ & $\begin{array}{l}{[4,18} \\
]\end{array}$ \\
\hline $\begin{array}{l}\mathrm{b} \\
\mathrm{c} \\
\mathrm{d}\end{array}$ & $\begin{array}{l}\text { Knurled diamond } \\
\text { pyramids, } \\
\text { longitudinal fins, } \\
\text { cylindrical wire } \\
\text { wrapping, } \\
\text { (RF: } 1.07 \text { to } 3.37 \text { ) }\end{array}$ & 3.0 & 6.3 & $\begin{array}{l}200 \text { to } \\
1,800\end{array}$ & $\begin{array}{l}\text { (e) } 1,050 \text { to } \\
10,500 \\
\text { (f) } 4,500 \text { to } \\
71,000 \\
\text { (g) } 600 \text { to } \\
250,000\end{array}$ & $\begin{array}{c}\text { (b) } S h=R e S c^{0.356} L e^{-2.0} \\
\text { (c) } S h=0.0062 R e S c^{0.356} \\
\text { d) } S h=0.714 R e^{0.61} S c^{0.356} L e^{-0.2}\end{array}$ & $\begin{array}{l}\text { Copper } \\
\text { deposition }\end{array}$ & $\begin{array}{l}\text { Gabe \& } \\
\text { Makanjou } \\
\text { la }\end{array}$ & {$[57]$} \\
\hline e & $\begin{array}{l}\text { Packed bed of } \\
\text { carbon particles }\end{array}$ & NA & NA & NA & $\begin{array}{l}100 \text { to } \\
500,000\end{array}$ & $S h=0.454 R e^{0.58} S c^{0.333}\left(\frac{d_{h}}{2 \beta r_{m}}\right)^{0.58}\left(\frac{d_{h}}{r_{2}-r_{1}}\right)^{1.12}\left(\frac{d}{d_{h}}\right)$ & $\begin{array}{l}\text { Copper } \\
\text { deposition }\end{array}$ & Kreysa & {$[58]$} \\
\hline$f$ & 100 ppi RVC & 1.0 & 1.2 & $\begin{array}{l}250 \text { to } \\
2,500\end{array}$ & $\begin{array}{l}1,000 \text { to } \\
10,000\end{array}$ & $S h=0.44 R e^{0.63} S c^{0.333}$ & $\begin{array}{l}\text { Copper } \\
\text { deposition }\end{array}$ & $\begin{array}{l}\text { Nahlé, } \\
\text { Reade \& } \\
\text { Walsh }\end{array}$ & {$[25]$} \\
\hline g & $\begin{array}{l}\text { Expanded metal } \\
\left(\mathrm{A}_{\mathrm{e}}=5.5-16.3 \mathrm{~cm}^{-}\right. \\
\left.{ }^{1}\right)\end{array}$ & $3.5^{*}$ & $\begin{array}{l}3.2 \text { to } \\
3.7\end{array}$ & 100 to 900 & $\begin{array}{l}4,800 \text { to } \\
92,000\end{array}$ & $S h=1.356 R e^{0.63} S c^{0.333}\left(\frac{d_{h}}{2 r_{m}}\right)^{0.63}\left(\frac{A c}{r_{m}}\right)^{0.94}\left(\frac{d}{d_{h}}\right)$ & $\begin{array}{l}\text { Ferricyanide } \\
\text { reduction }\end{array}$ & $\begin{array}{l}\text { Grau \& } \\
\text { Bisang }\end{array}$ & [59] \\
\hline h & $\begin{array}{l}\text { Metal powder } \\
\text { deposits }\end{array}$ & $\begin{array}{l}6.3 \text { to } \\
74\end{array}$ & $\begin{array}{l}4.3 \text { to } \\
77\end{array}$ & $\begin{array}{l}180 \text { to } \\
1,230\end{array}$ & $\begin{array}{l}80,000 \text { to } \\
5000,000\end{array}$ & $S h=0.079 R e^{0.92} S c^{0.356}$ & $\begin{array}{l}\text { Copper } \\
\text { deposition }\end{array}$ & $\begin{array}{l}\text { Holland \& } \\
\text { Walsh }\end{array}$ & $\begin{array}{l}{[60-} \\
62]\end{array}$ \\
\hline
\end{tabular}

\section{Table 2. Selected RCE studies of mass transport.}

$A_{c}$ is the aperture of short mesh of the expanded metal of RCE, $A_{e} i s$ the electrode area per unit electrode volume, $d$ is the diameter of the RCE. $d_{b}$ the base diameter, $d_{h}$ the hydraulic diameter, $d_{p}$ the particle diameter, $l_{b}$ the base length, $R F$ the roughness factor (area of rough surface divided by the area of a corresponding smooth electrode), $r_{l}$ the internal radius of the expanded metal RCE, $r_{2}$ the external radius of the expanded metal of $\mathrm{RCE}, r_{m}$ the mean RCE radius and $\beta$ the porosity. NA: Not available. Figure 6 shows corresponding mass transport correlations. After Low et al. $[16]$. 


\begin{tabular}{|l|c|}
\hline Geometry (fully roughened surface) & Dimensionless group correlation \\
\hline Rotating cylinder electrode & $S h=0.016 R e^{0.95} S c^{0.33}$ \\
\hline Pipe flow & $S h=0.02 R e^{0.9} S c^{0.33}$ \\
& $S h=0.005 R e^{1.0} S c^{0.33}$ \\
\hline Impinging jet & $S h=0.007 R e^{0.96} S c^{0.33}$ \\
\hline 180 deg bend in $22.6 \mathrm{~mm}$ pipe & $S h=0.065 R e^{1.02} S c^{0.33}$ \\
\hline
\end{tabular}

Table 3. Dimensionless group correlations describing mass transfer to rough surfaces for various geometries in the form $S h=a R e^{b} S c^{c}$. After Poulson [64]. 


\begin{tabular}{|c|c|c|c|c|c|}
\hline \multirow[t]{2}{*}{$\begin{array}{l}\text { RCE } \\
\text { material }\end{array}$} & \multirow[t]{2}{*}{ RCE surface state } & \multicolumn{2}{|c|}{ Times / s } & \multicolumn{2}{|c|}{$\begin{array}{c}\text { Potential range vs. SCE } \\
\qquad / \mathrm{V}\end{array}$} \\
\hline & & Zone (1) & Zone (2) & Zone (1) & Zone (2) \\
\hline $\mathrm{Cu}$ & Polished & $8 \pm 3$ & $18 \pm 2$ & $-0.26 \pm 0.04$ & $-0.56 \pm 0.04$ \\
\hline $\mathrm{Cu}$ & $\begin{array}{l}\text { Polished then } \\
\text { equilibrated }\end{array}$ & - & - & - & - \\
\hline $90-10 \mathrm{Cu}-\mathrm{Ni}$ & Polished & - & $79 \pm 4$ & - & $-0.34 \pm 0.06$ \\
\hline $90-10 \mathrm{Cu}-\mathrm{Ni}$ & $\begin{array}{l}\text { Polished then } \\
\text { equilibrated }\end{array}$ & $10 \pm 2$ & - & $-0.18 \pm 0.02$ & - \\
\hline NAB & Polished & $17 \pm 4$ & $39 \pm 3$ & $-0.25 \pm 0.06$ & $-0.48 \pm 0.12$ \\
\hline NAB & $\begin{array}{l}\text { Polished then } \\
\text { equilibrated }\end{array}$ & - & - & - & - \\
\hline
\end{tabular}

Table 4. Data extracted from galvanostatic, electrometric reduction of surface films on copper, 90-10 copper nickel and NAB alloy RCE surfaces after wet polishing or wet polishing followed by equilibration in filtered seawater at open-circuit and a temperature of 298 K (See Figure 9). Data taken from Kear [35]. 


\begin{tabular}{|l|c|c|c|c|}
\hline RCE Material & \multicolumn{4}{|c|}{ Film thickness / nm } \\
\cline { 2 - 5 } (Surface state) & $\mathbf{C u}(\mathbf{O H})_{2}$ & $\mathbf{C u}_{2} \mathbf{O}$ & $\mathbf{C u O}$ & Total \\
\hline $\begin{array}{l}\mathrm{Cu} \\
\text { (Polished) }\end{array}$ & - & $1.1 \pm 0.4$ & $0.6 \pm 0.1$ & $1.7 \pm 0.5$ \\
\hline $\begin{array}{l}\mathrm{Cu} \\
\text { (Equilibrated) }\end{array}$ & - & - & - & 0.0 \\
\hline $\begin{array}{l}90-10 \text { Cu-Ni } \\
\text { (Polished) }\end{array}$ & - & $9.0 \pm 0.5$ & - & $9.0 \pm 0.5$ \\
\hline $\begin{array}{l}90-10 \text { Cu-Ni } \\
\text { (Equilibrated) }\end{array}$ & $0.6 \pm 0.1$ & - & - & $0.6 \pm 0.1$ \\
\hline $\begin{array}{l}\text { NAB } \\
\text { (Polished) }\end{array}$ & $0.8 \pm 0.2$ & $3.2 \pm 0.2$ & - & $4.0 \pm 0.4$ \\
\hline $\begin{array}{l}\text { NAB } \\
\text { (Equilibrated) }\end{array}$ & - & - & - & 0.0 \\
\hline
\end{tabular}

Table 5. Film thickness of corrosion product layers at copper, 90-10 copper nickel and NAB RCE surfaces (estimated from electrometric data) after wet polishing and subsequent equilibration at open-circuit in filtered seawater at 298 K. Data taken from Kear [35]. 


\section{Figure captions}

Figure 1. A definition sketch for a rotating cylinder electrode, RCE, indicating important features, dimensions and operational variables. The common case of an inner RCE rotating about a vertical axis is considered, the active surface being the outer surface. The provision of a reference electrode (RE) facilitates measurement or control of the RCE potential. Commonly, the outer electrode is inert and supports oxygen or hydrogen evolution.

Figure 2. A time-line showing selected developments in the RCE, highlighting fundamental science and engineering as well as corrosion and protection studies. 1954: Dimensionless group correlation of RCE mass transfer by Eisenberg et al. [4]; 1971: Controlled surface roughness mass transfer study by Kappesser et al. [5]; 1974: Applied RCE review by Gabe [6]; 1978: Compilation of mass transport correlations by Selman and Tobias [7]; 1983: RCE development review by Gabe and Walsh [8]; 1984: RCE study on controlled velocity corrosion by Silverman [9]; 1998: RCE continued development review by Gabe et al. [10]; 2004: RCE corrosion review by Silverman [11]; 2004: Extensive copper, NAB and stainless steel corrosion studies in chloride solutions at RCEs by Kear et al. [12-15]; 2005: RCE electrodeposition of metals review by Walsh et al. [16]; 2013: Erosion-corrosion synergy rates in nanofluids by Rashidi et al. [17].

Figure 3. The interactive aspects of RCE characteristics and cell design, including electrode features, electrolyte characteristics and cell conditions.

Figure 4. Classification of RCE geometries. a) single RCE (which may have a smooth, textured, pre-pitted or roughened surface), b) a double RCE (where WE1 and WE2 can be disparate sizes or dissimilar metals), c) a combined RDE and RCE on a common rotation axis and d) a hybrid RCE and line microelectrode RCE. The RCE surface may be modified by e) recessing, stepping, sleeving or crevice formation, f) a pre-coated $\mathrm{RCE}$ or one forming a film may be forming a porous film; the RCE surface may be impinged by g) an electrolyte jet or h) a solid particle or gas stream. 
Figure 5. Examples of laboratory RCEs. a) A three-compartment cell featuring: a. reference electrode compartment fitted with a Luggin-Haber capillary, b. counter/auxiliary electrode compartment, c. RCE assembly, d. aeration/nitrogen purge diffuser, e. in-situ aeration diffuser and f. a thermostatic water jacket. Reproduced with permission from Kear [35]. b) A simple RCE constructed from a circular metal pipe section. After Walsh and Ponce de León [38].

Figure 6. Comparison of mass transport correlations to rotating cylinder electrodes. The Sherwood and Reynolds numbers are based on the diameter of the inner rotating cylinder electrode. The various correlations are due to different types of surface roughness on the RCE surface. a. hydrodynamically smooth surfaces; Eisenberg et al. $[4,18]$. b. knurled diamond pyramids, c. longitudinal fins, and d. cylindrical wire; Gabe and Makanjuola [57], e. packed bed RCE reactor; Kreysa [58], f. porous 3-dimensional reticulated vitreous carbon material; Nahlé et al. [25], g. expanded metal; Grau and Bisang [59], h. metal powder deposits; Holland and Walsh [60-62].

Figure 7. A laboratory rotating cylinder Hull (RCH) cell for current distribution in metal alloy deposits at 298 K. a) The cathode is an RCE (316 stainless steel, $0.6 \mathrm{~cm}$ diameter, $8.0 \mathrm{~cm}$ length and the counter electrode is a concentric cylindrical anode $(\mathrm{Pt} / \mathrm{Ti}, 0.1 \mathrm{~cm}$ thickness, $5.2 \mathrm{~cm}$ inside diameter, $2.5 \mathrm{~cm}$ height). The highlighted 2-D planar area is the computational domain used in a numerical simulation, b) Generation of 2-D triangular meshes. The enlarged circle shows the meshes generated inside the diffusion layer region and free electrolyte region. The bold lines indicate the electrode surfaces, all other surfaces are insulators. c) Dimensionless current density $v s$. distance profiles for three types of current distribution at $750 \mathrm{rev} \mathrm{min}^{-1}$. - uniform current distribution; ..... primary current distribution; ----- secondary current distribution; and -...- tertiary current distribution. Reproduced with permission from Low et al. [47]. 
Figure 8. Open-circuit corrosion potential of copper and alloys as a function of time at an RCE, showing the importance of film formation at 298 K. a) Copper in aerated, filtered seawater as a function of RCE rotation rate. The open data points indicate the locus of inflection at each rotation rate, b) 90-10 copper nickel, c) NAB alloy and d) Ferralium SD40 superduplex stainless steel. Reproduced with permission from Kear [35].

Figure 9. Typical plots showing the galvanostatic reduction of oxide layers on copper, 90-10 copper nickel and nickel aluminium bronze during wet polishing and after equilibration at the open-circuit potential in air-saturated, filtered seawater at 298 K. Reproduced with permission from Kear [35].

Figure 10. Linear polarisation resistance derived corrosion current density data as a function of RCE peripheral velocity for various materials in seawater at 298 K. $d=2.0 \mathrm{~cm} ; 100<\omega<1400 \mathrm{rev}^{\mathrm{min}^{-1}} ; 8<U<111 \mathrm{~cm} \mathrm{~s}^{-1}$. Reproduced with permission from Kear [35].

Figure 11. The effect of RCE peripheral velocity on corrosion inhibition. EIS Nyquist

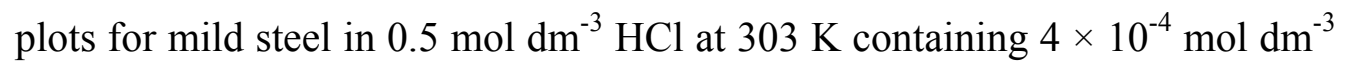
4-amino-5-phenyl-4H-1, 2, 4-trizole-3-thiol (APTT), showing the effect of peripheral velocities of 25,50 and $100 \mathrm{~cm} \mathrm{~s}^{-1}$. Reproduced with permission from Musa et al. [107].

Figure 12. Variation in corrosion rate (weight loss) of a chromium steel during erosion -corrosion at an RCE with electrode potential, showing data in $1 \mathrm{~mol} \mathrm{dm}^{-3}$ $\mathrm{NaOH}$ containing $273 \mathrm{~g} \mathrm{dm}^{-3}$ alumina at ambient temperature ( $c a .298 \mathrm{~K}$ ), showing the effect of alumina particle size. a) $50 \mu \mathrm{m}$, b) $100 \mu \mathrm{m}$ and c) $150 \mu \mathrm{m}$ alumina particle size at an RCE peripheral velocity of $6 \mathrm{~m} \mathrm{~s}^{-1}$. The overall erosion-corrosion rate, $K_{\text {total }}$ is considered as an addition of the rates of pure erosion, $K_{\text {erosion }}$ pure corrosion, $K_{\text {corr }}$ and a synergy term $\Delta K_{\text {synergy. }}$ After Yuan and Stack [123]. 
Figure 13. The use of a smooth mild steel RCE to study erosion-corrosion in a turbulent nanofluid. Comparison of the synergistic effect of erosion and corrosion in sea water with (filled circle) and without (filled square) $1 \mathrm{~g} \mathrm{dm}^{-3} 20$ nm spheroidal $\mathrm{Al}_{2} \mathrm{O}_{3}$ nanoparticles. $6 \mathrm{~cm}$ diameter, $56.6 \mathrm{~cm}^{2}$ area $\mathrm{RCE}$ at 415 rev $\min ^{-1}\left(U=130 \mathrm{~cm} \mathrm{~s}^{-1}\right)$ at $298 \mathrm{~K}$. Reproduced with permission from Rashidi et al. [17].

Figure 14. Protective coating studies at an RCE. Tafel polarization measurements of a) bare copper, b) copper/HDI (poly hexamethylene diisocyanate), and c) copper/reduced graphene in $3.5 \% \mathrm{NaCl}$ solution at $298 \mathrm{~K}$. Reproduced with permission from Sahu et al. [144].

Figure 15. An example of a bimetallic RCE to study galvanic corrosion in seawater. a) Mean single metal and coupled, bimetallic potential transients of 90-10 coppernickel and NAB as a function of bimetallic RCE rotation rate. b) Log-log plots describing the impressed current density $v s$. time behaviour at the copper/NAB bimetallic couples as a function of electrode rotation rate (200-1400 rev $\left.\mathrm{min}^{-1}\right)$ and applied potential (-0.44 to $-0.59 \mathrm{~V} v s$. SCE). Experimental data at $298 \mathrm{~K}$ are compared to the predicted behaviour. Reproduced with permission from Kear et al. [35]. 


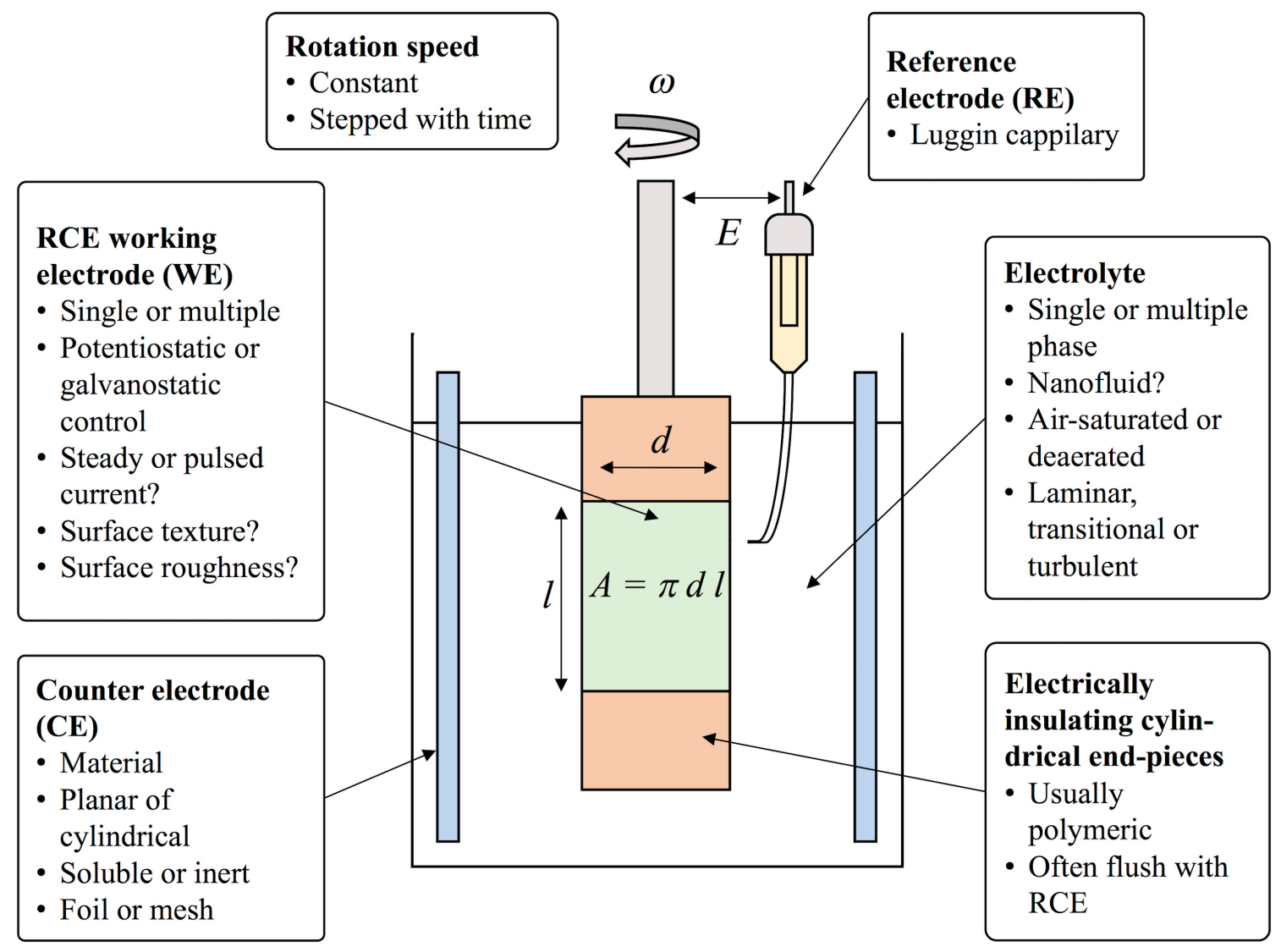

Figure 1 


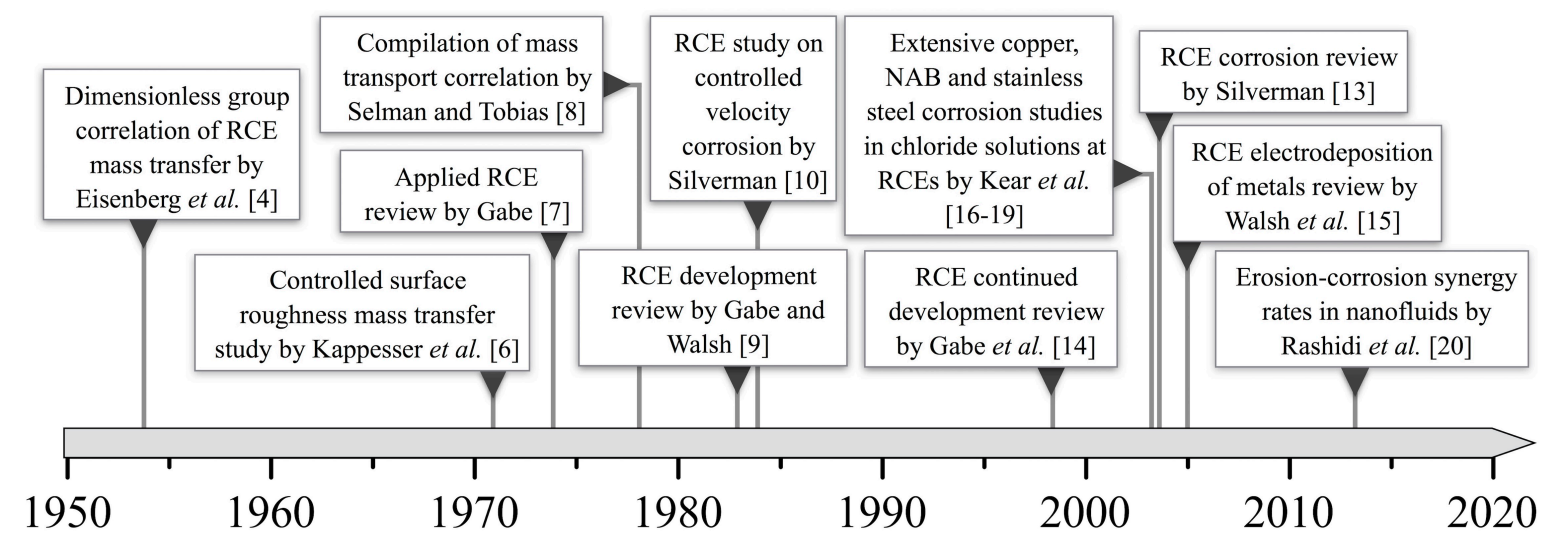

Figure 2 


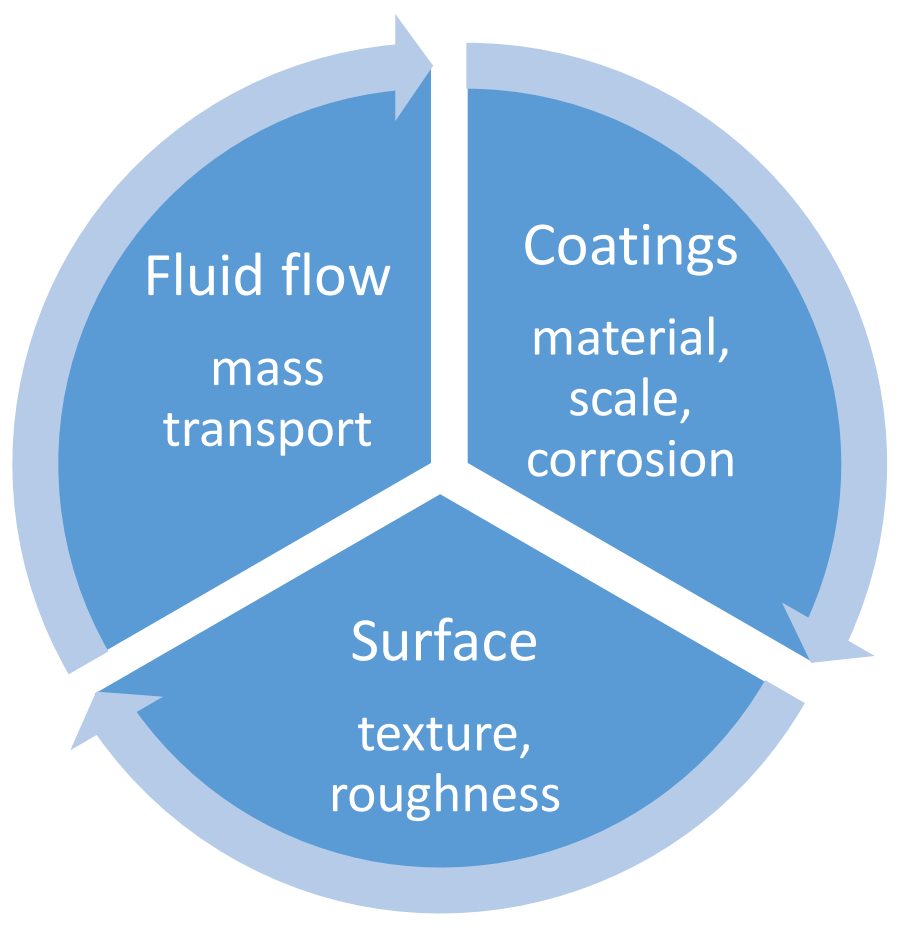

Figure 3 

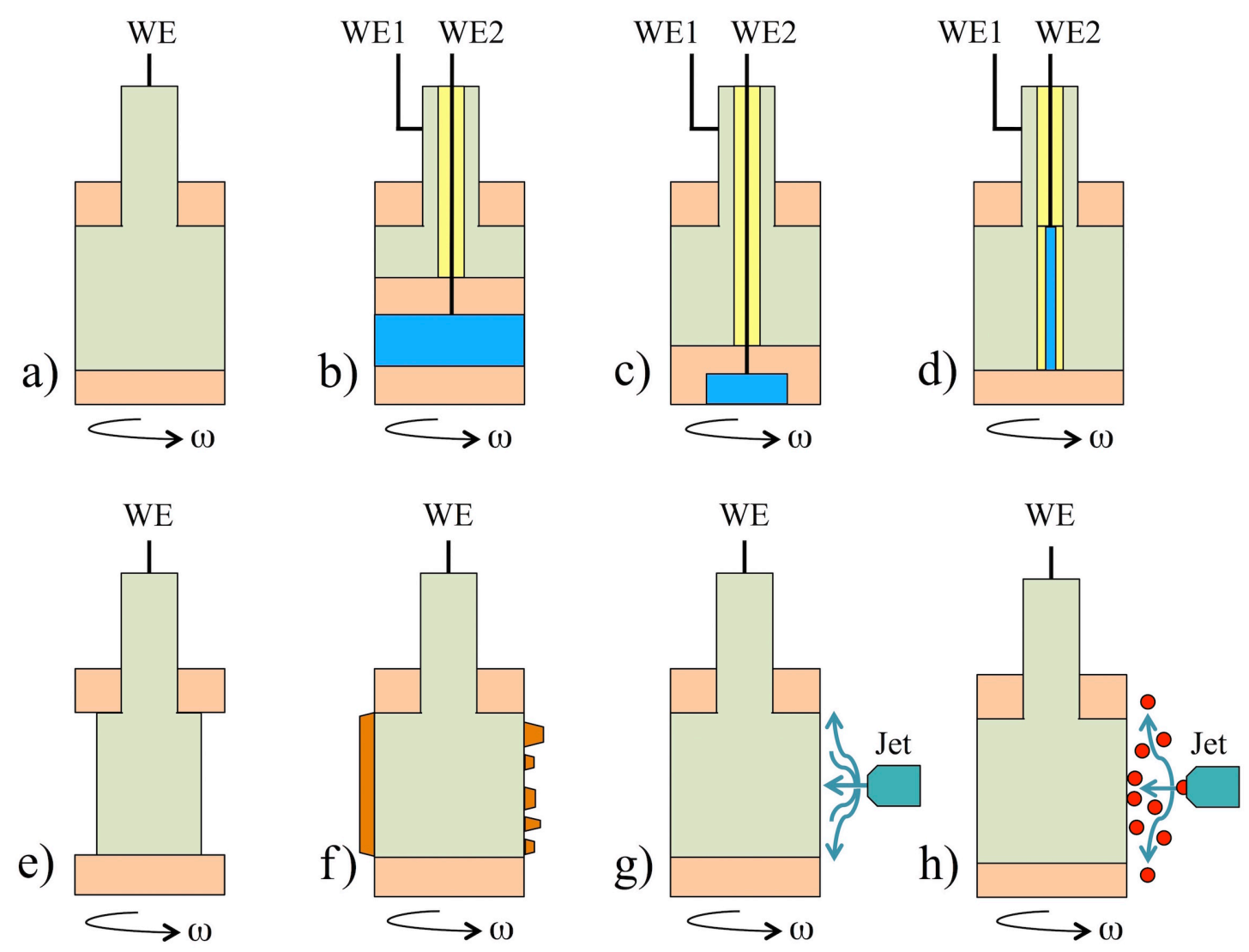

Main RCE

Polymer spacer Electrical insulation Other electrode

Figure 4 


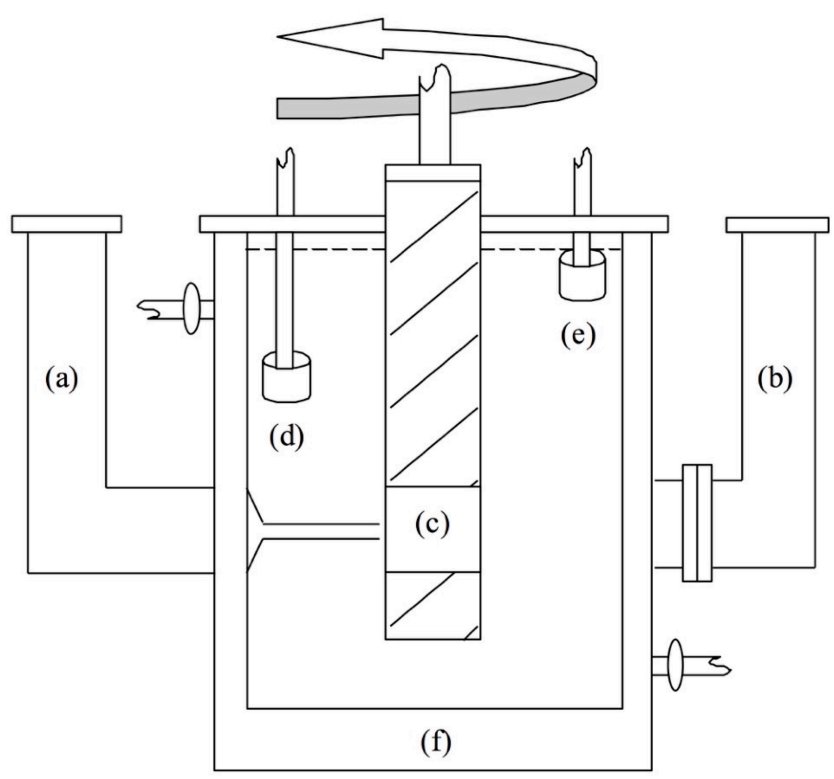

Figure 5a)

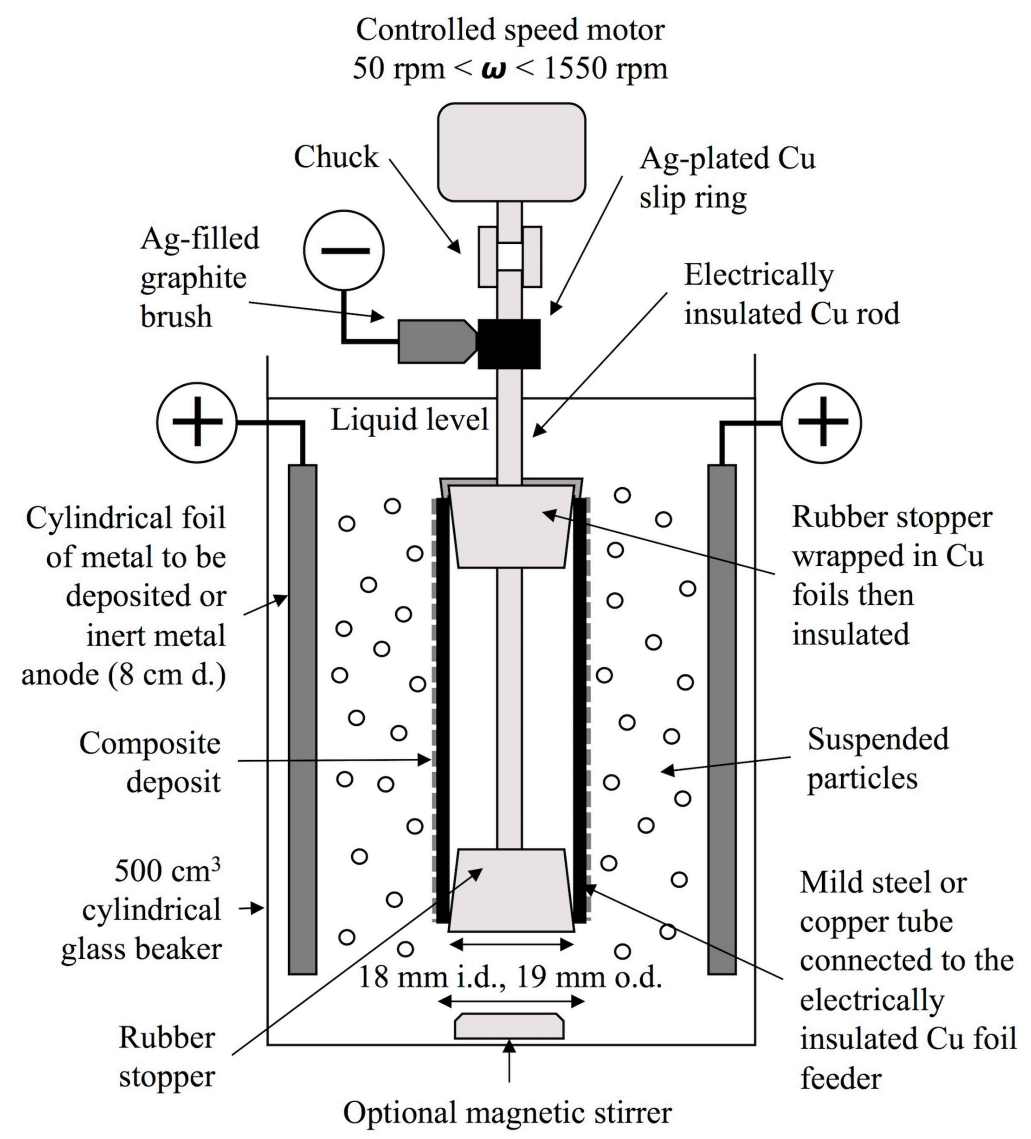

Figure 5b) 


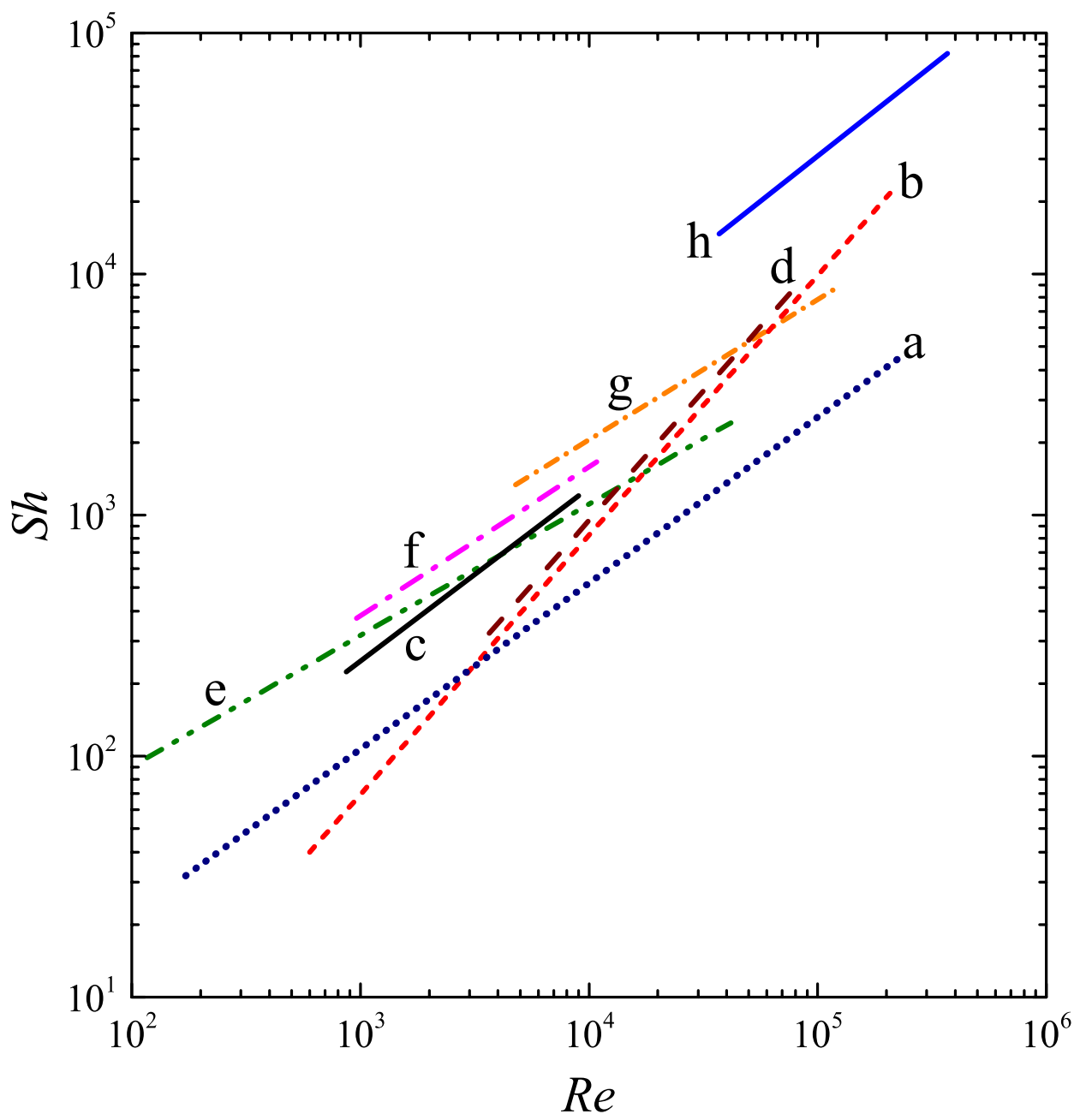

Figure 6 


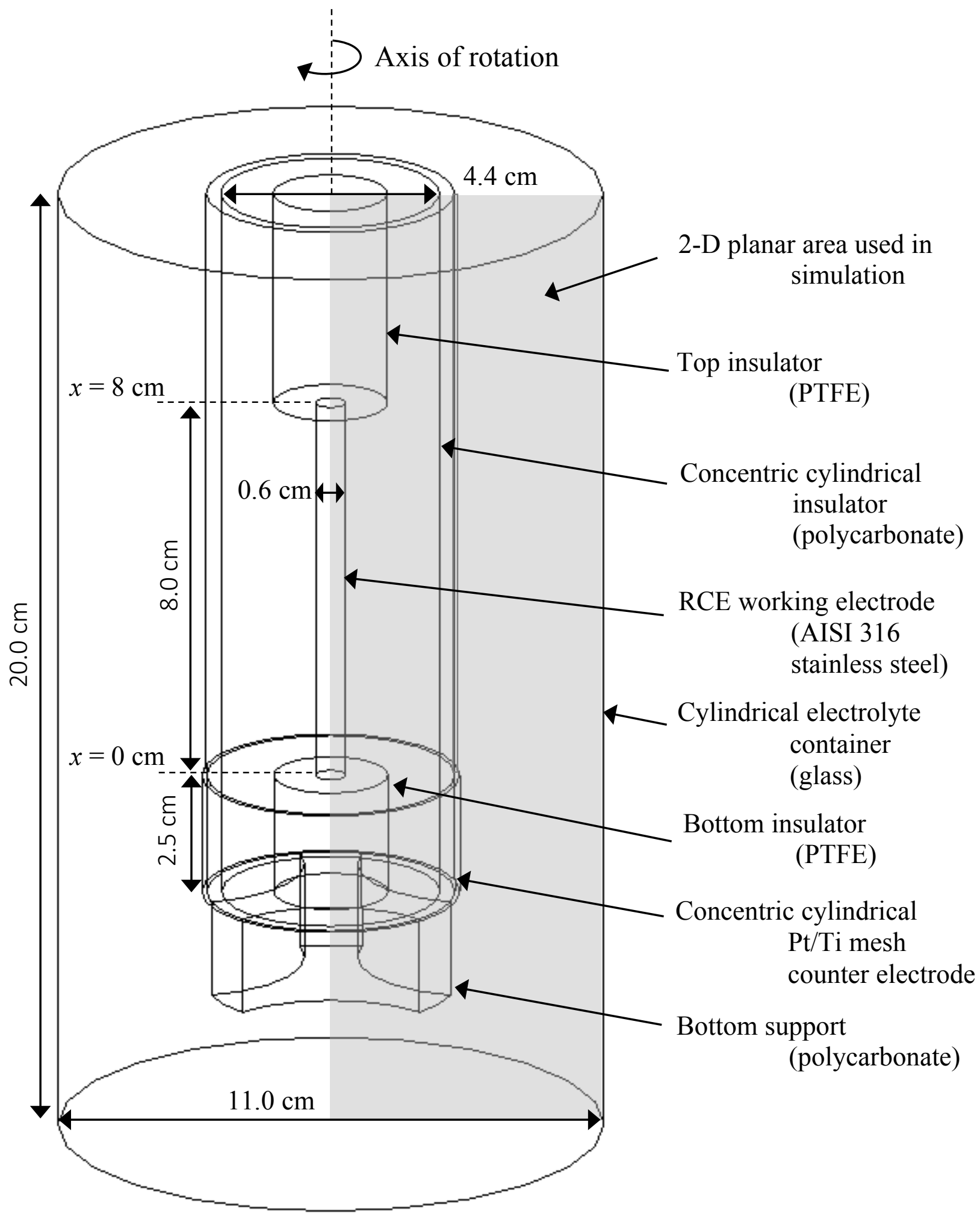

Figure 7a) 


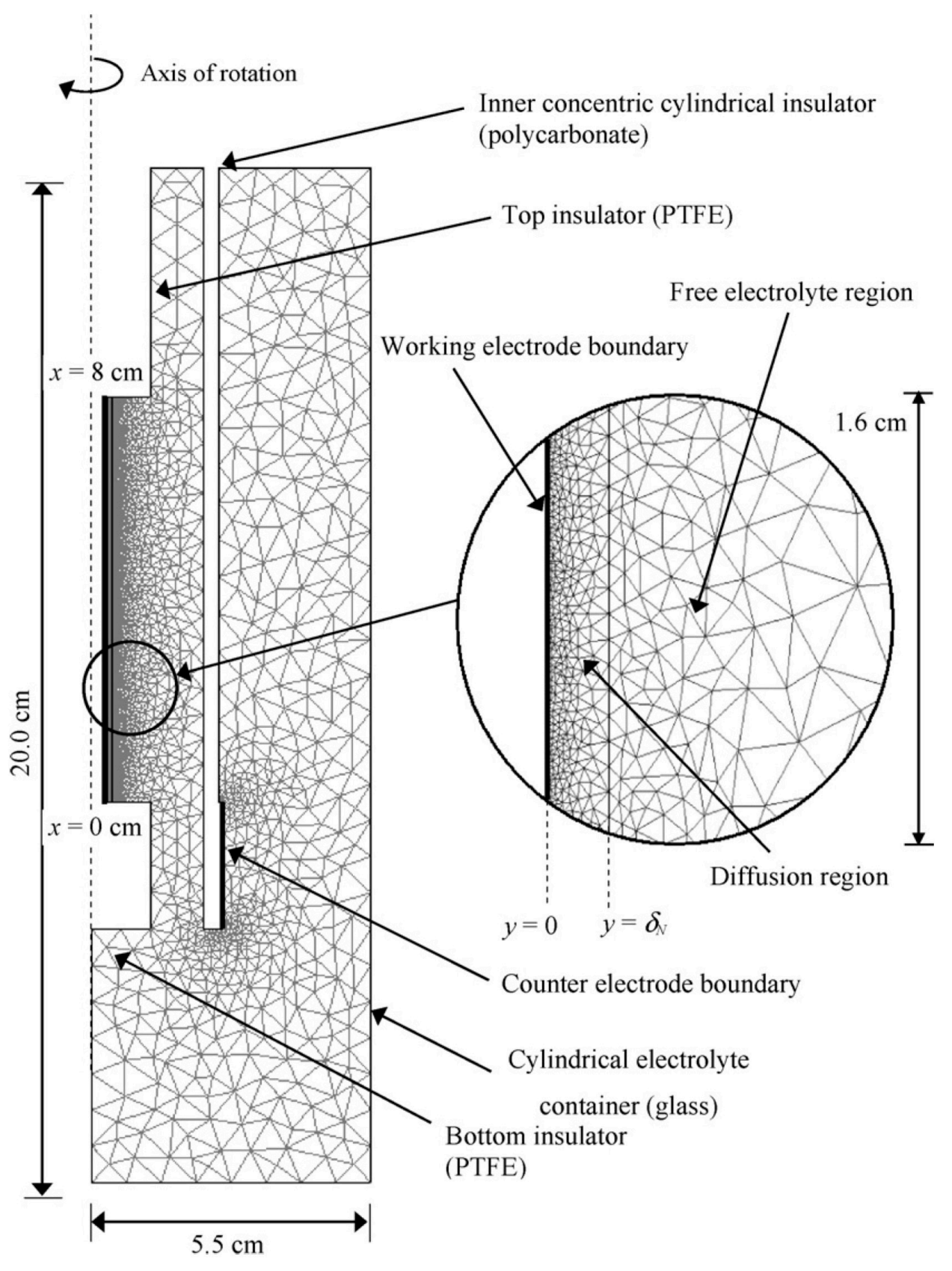

Figure 7b) 


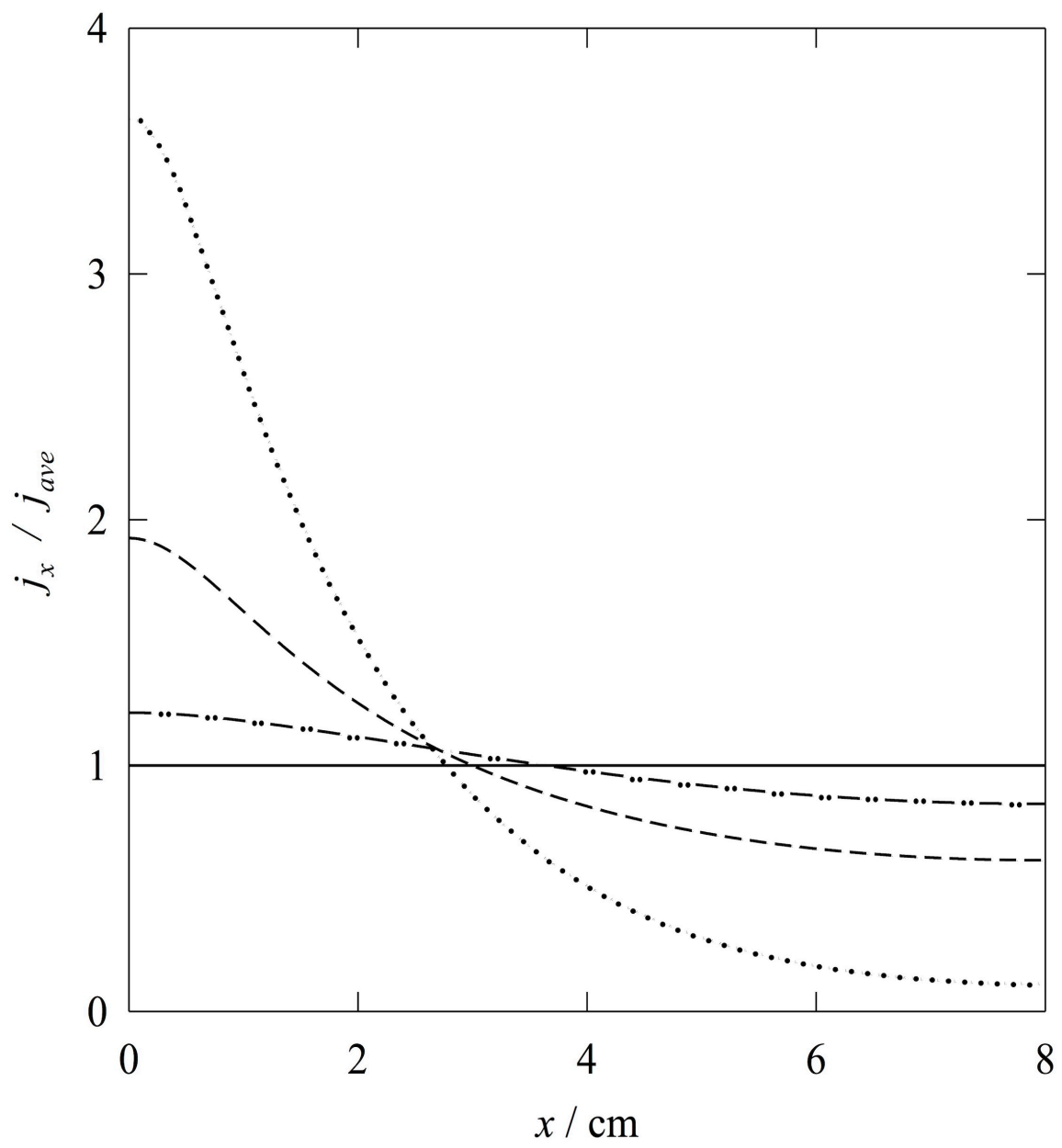

Figure 7c) 


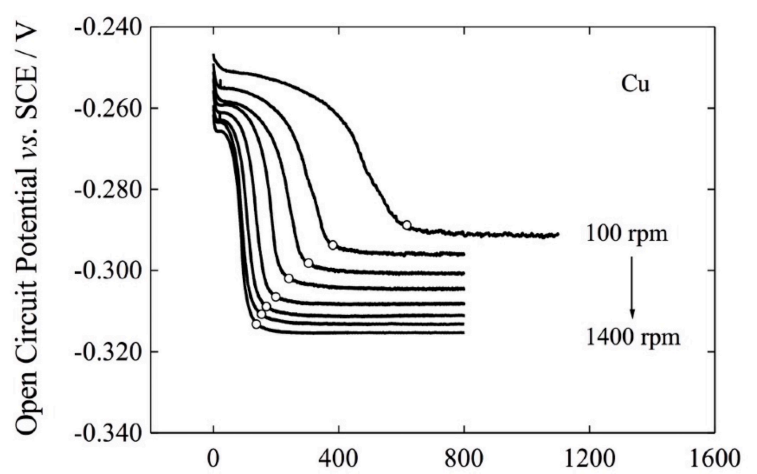

a) Time Post Initiation of Rotation / s

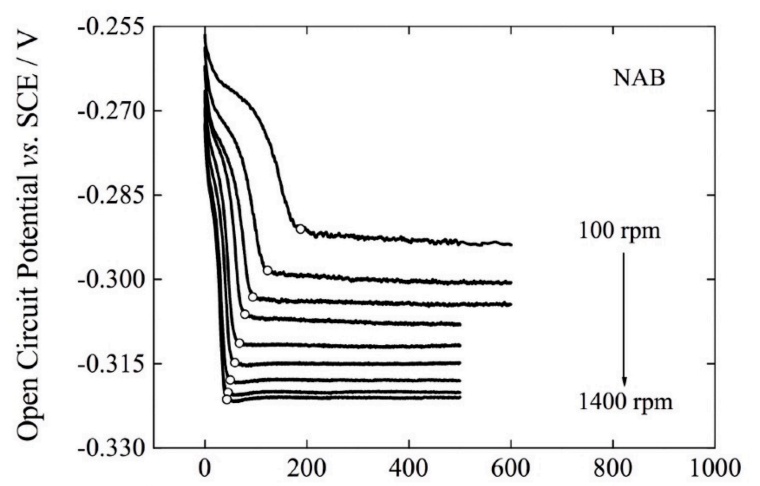

c) Time Post Initiation of Rotation / $\mathrm{s}$

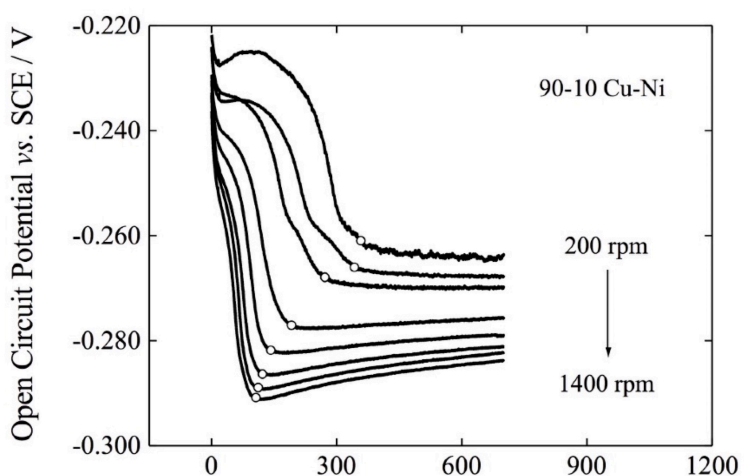

b) Time Post Initiation of Rotation / s

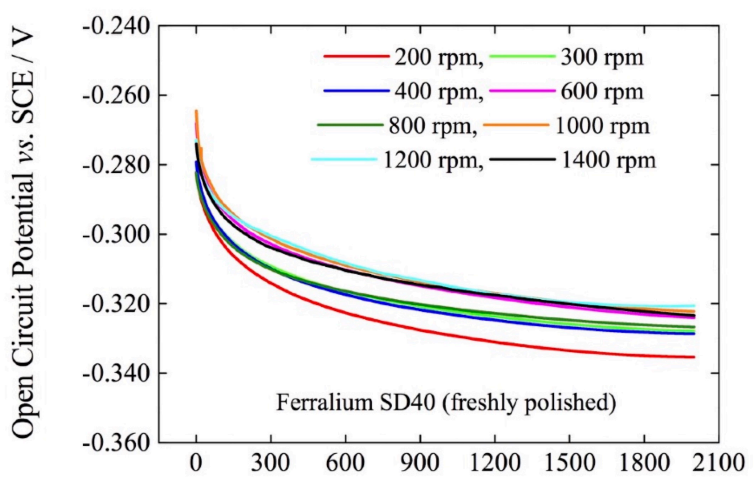

d) Time Post Initiation of Rotation / s

\section{Figure 8}




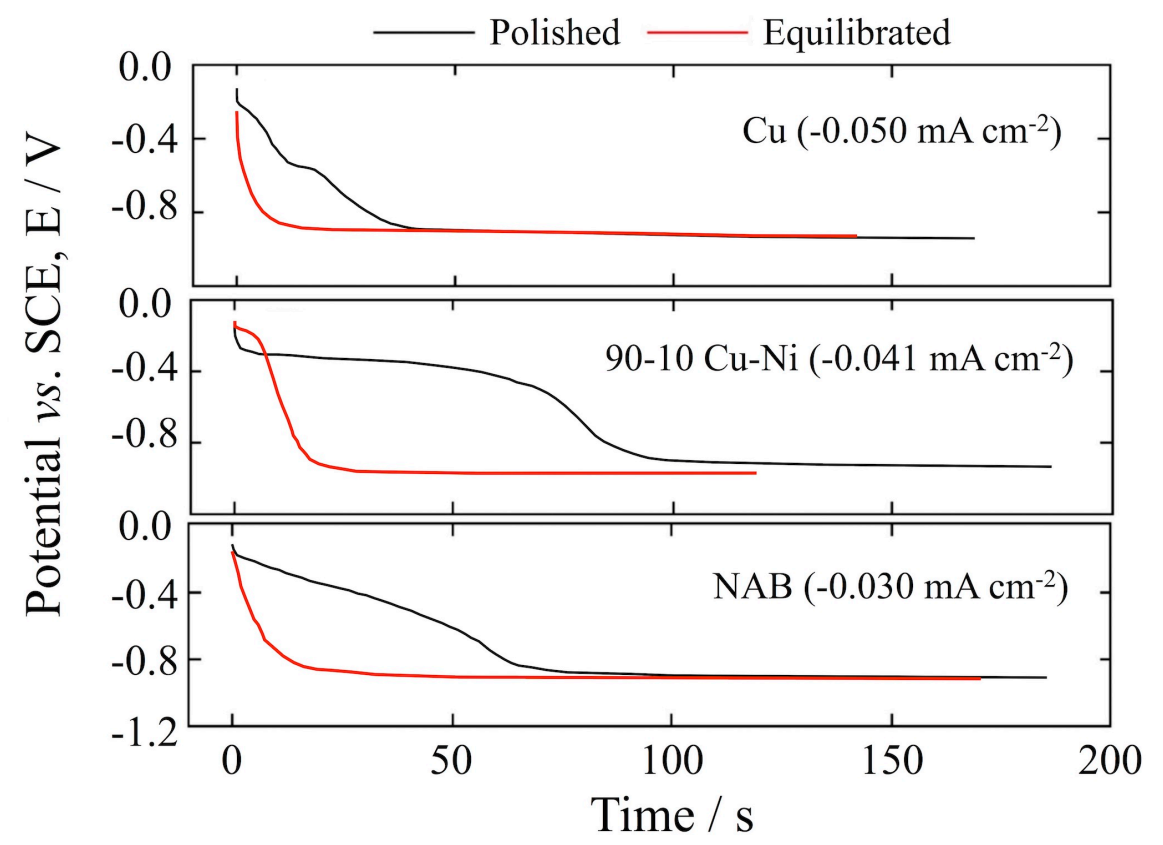

Figure 9 


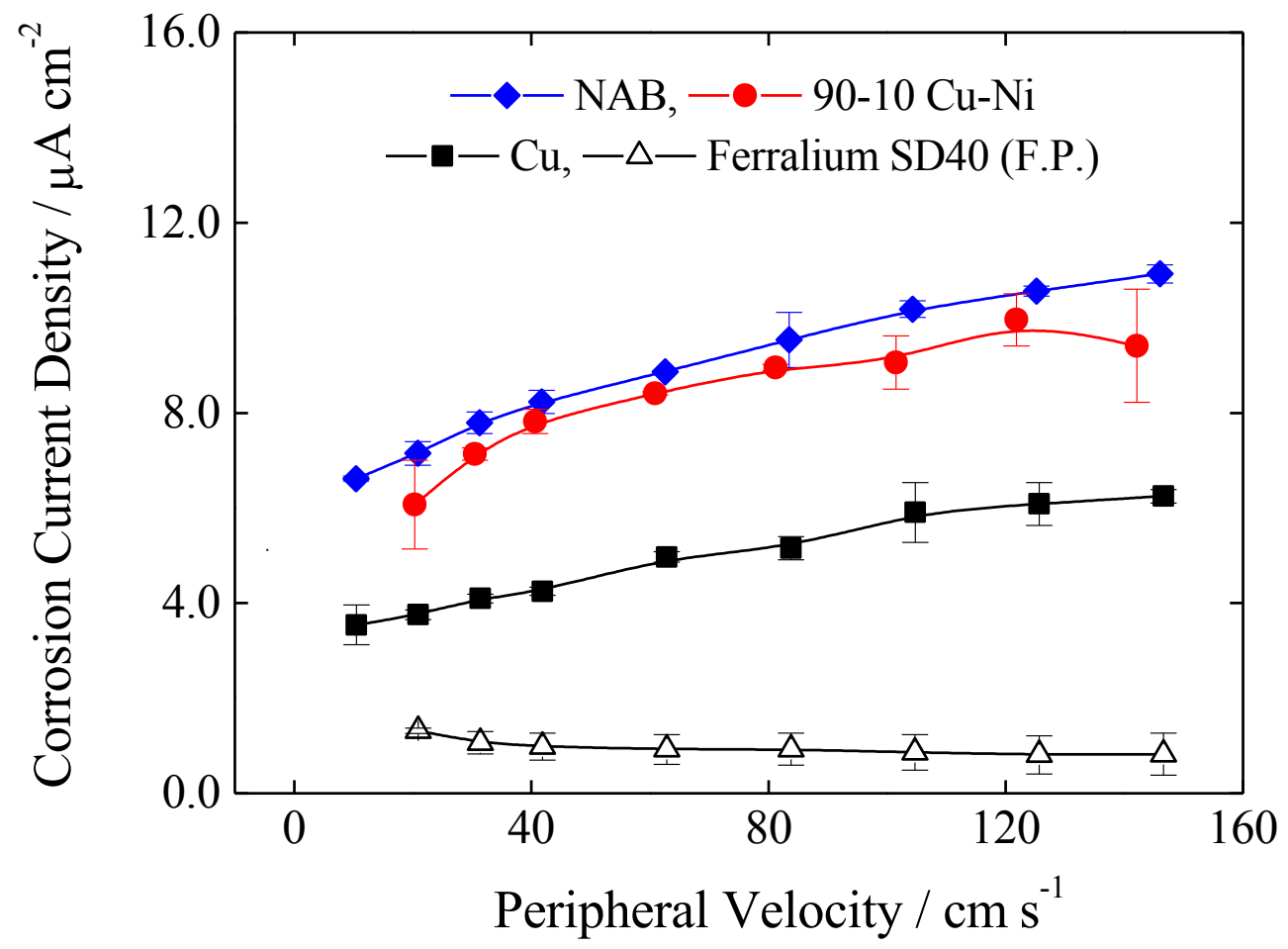

Figure 10 

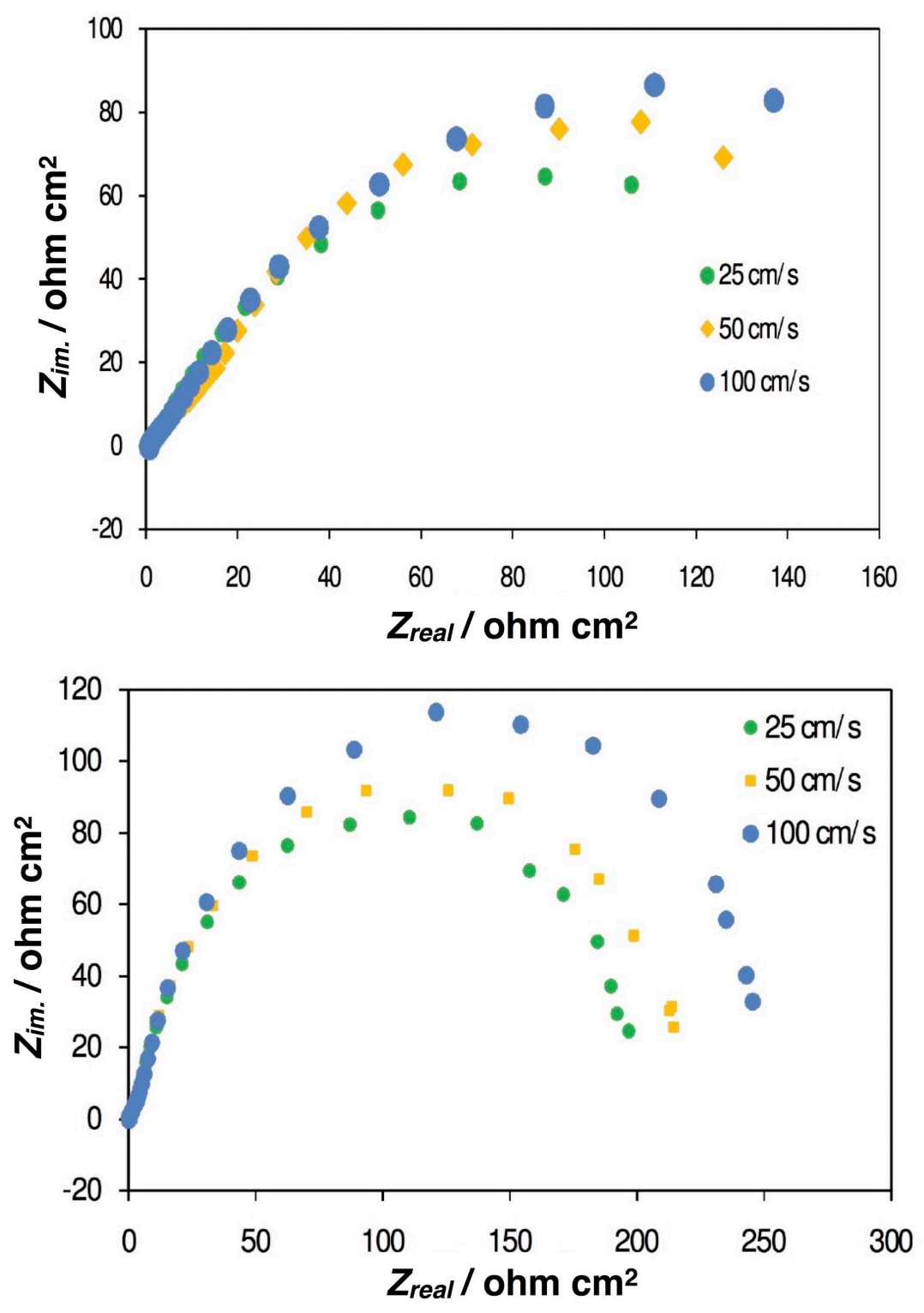

Figure 11 


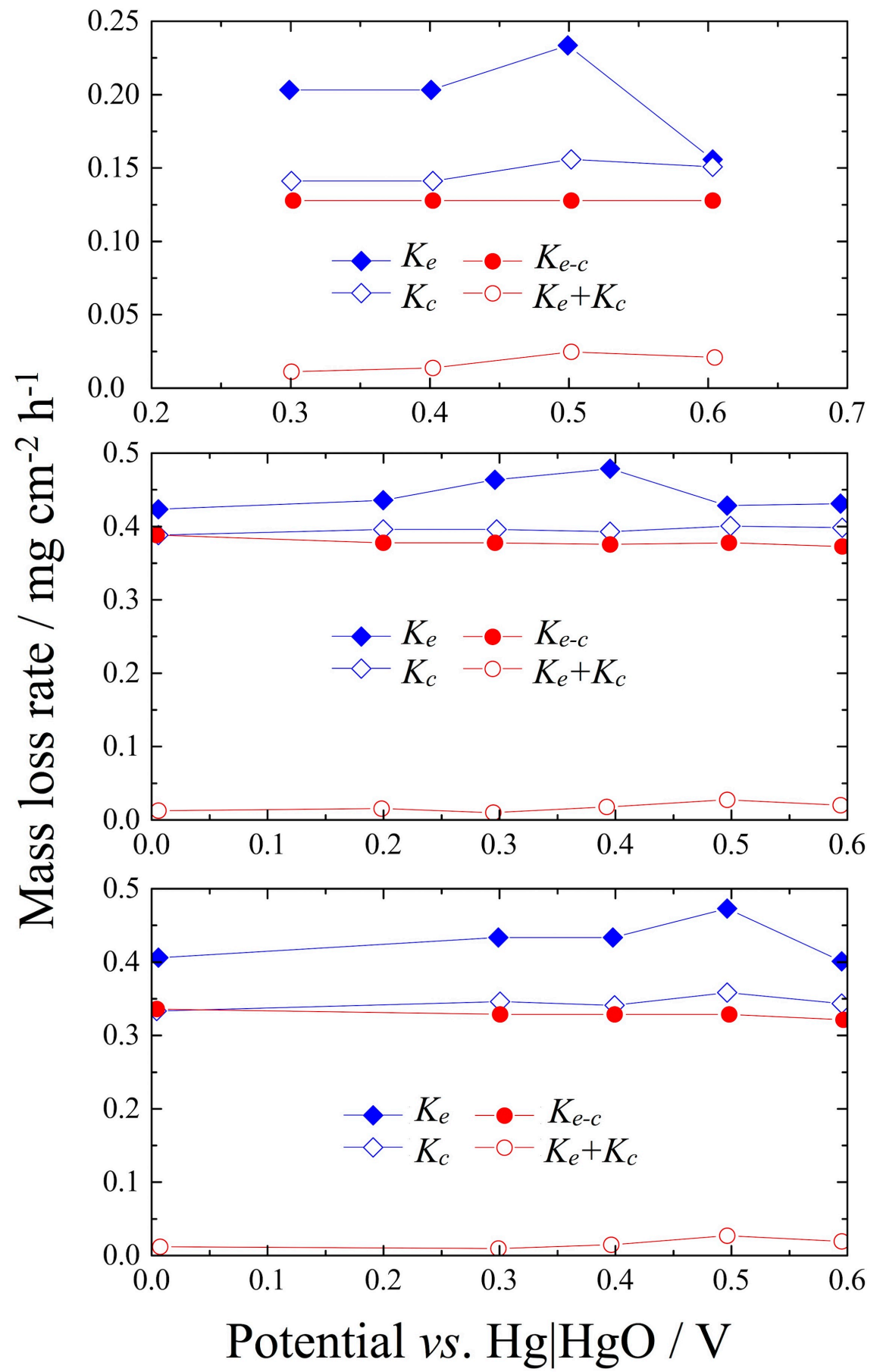

Figure 12 


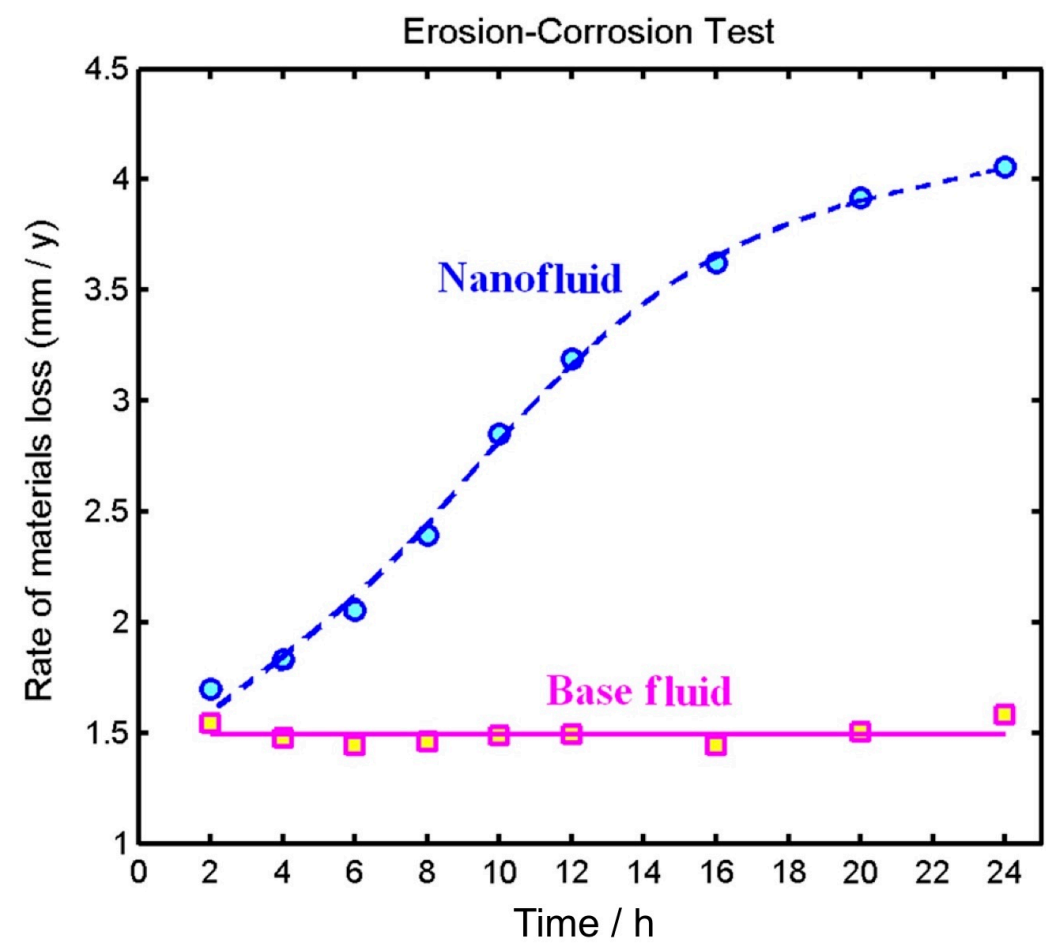

Figure 13 


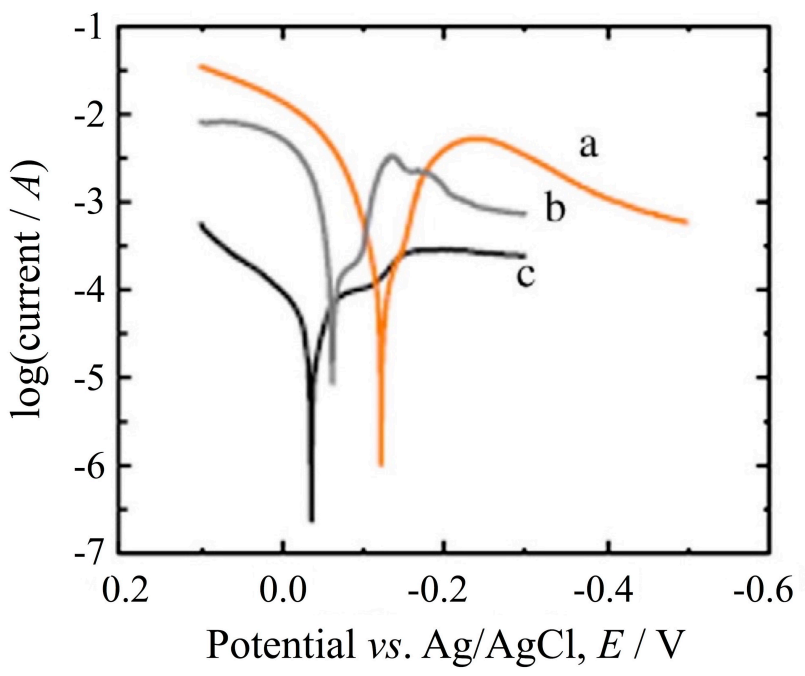

Figure 14 

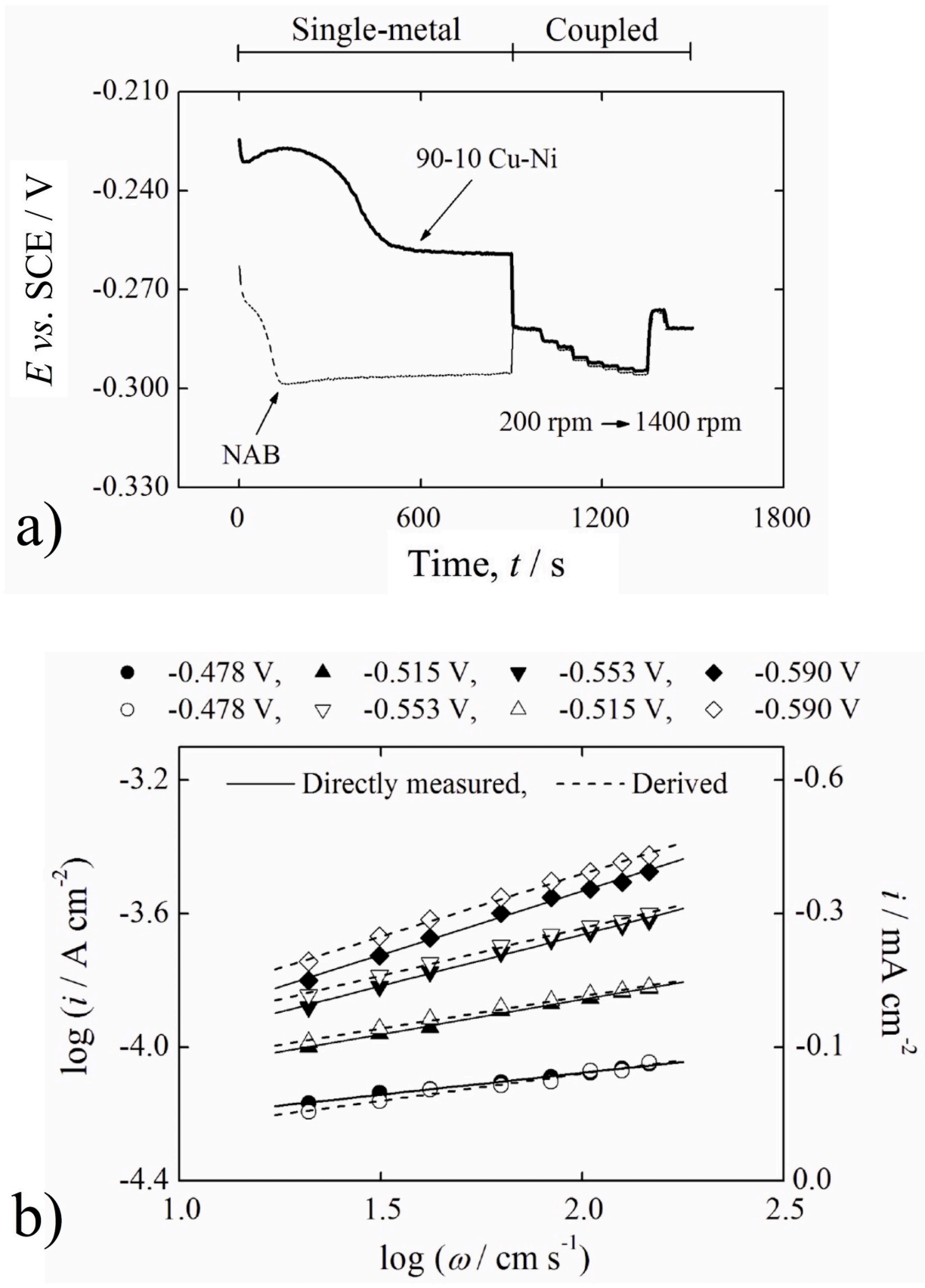

Figure 15 